Law \& Economics Working Papers

Law \& Economics Working Papers Archive:

2003-2009

\title{
Affirmative Action in American Law Schools: A Critical Response to Richard Sander's "A Reply to Critics"
}

\author{
Richard O. Lempert* \\ William C. Kidder ${ }^{\dagger}$ \\ Timothy T. Clydesdale \\ David L. Chambers**
}

\footnotetext{
*University of Michigan Law School, rlempert@umich.edu

$\dagger$ Equal Justice Society, williamkidder@equaljusticesociety.org

${ }_{\ddagger}$ College of New Jersey, clydesda@tcnj.edu

**University of Michigan Law School, dcham@umich.edu
}

This paper is posted at University of Michigan Law School Scholarship Repository.

http://repository.law.umich.edu/law_econ_archive/art60 


\title{
Affirmative Action in American Law Schools
}

\section{A Critical Response to Richard Sander's “A Reply to Critics”}

\author{
Richard O. Lempert, ${ }^{*}$ William C. Kidder, ${ }^{* *}$ \\ Timothy T. Clydesdale, ${ }^{* * *} \&$ David L. Chambers ${ }^{* * * *}$
}

Authors' Note: This is a working paper representing our initial reactions to the reply essay by Richard Sander that was published in the same issue of the Stanford Law Review as our empirical critique of his article on law school affirmative action. As such, our views may be refined later and we encourage criticism of this working paper. To facilitate the readers' ability to track rather complicated back-and-forth arguments between Professor Sander and the four of us, quotations from Sander's reply essay are in RED ITALICS, and are followed by our response to each claim. (See article "The Real Impact of Eliminating Affirmative Action in American Law Schools: An Empirical Critique of Richard Sander's Study," Chambers et al, Stan. L. Rev. 57, no. 6 (2005): 1855-98.)

I.

\section{OUTLINE}

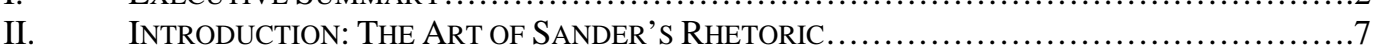

A. "Mismatch" as a Moving Target: First-Time Versus Eventual Bar Pass Rates........ 7

B. The Number of Black Lawyers: A Side Issue?...............................................................

C. Revisionism About Part VIII of Systemic Analysis................................9

D. Has Systemic Analysis been "thoroughly replicated"?...................................................10

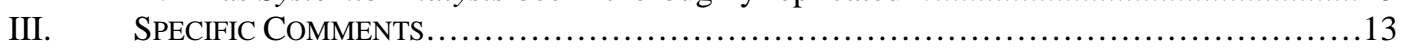

A. Arguments on the Mismatch Effect...................................................13

1. LSAT \& UGPA Explain 90\% of Black-White Differences?...............................13

2. Sander's Theory Versus Alternatives like "Stereotype Threat"...............20

3. Law School Grades: Questioning Causation and Curvilinear Effects............23

4. Selection Bias and Black-on-Black Comparisons.........................28

5. The Tiers in the Bar Passage Dataset......................................33

6. The Second-Choice Data......................................................34

B. Arguments on the Effects of Ending Affirmative Action...............................42

1. The Post-Affirmative Action Credential Gap is Sizeable.....................42

2. Why 2004 Admissions Data is Preferable to Sander's 2001 Data..............45

3. The Decline in Enrollments at Elite Law Schools..........................47

4. The Worsening Mismatch Effect?.......................................................................49

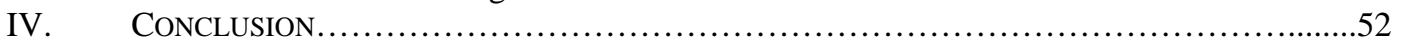

Eric Stein Distinguished University Professor of Law and Sociology at the University of Michigan, currently on leave as Division Director for the Social and Economic Sciences at the National Science Foundation. Lempert's work on this working paper was done while serving at the National Science Foundation, but any opinions, findings, conclusions, or recommendations expressed here are those of the authors and do not reflect the views of the National Science Foundation.

Senior Policy Analyst, University of California, Davis. Mr. Kidder began his research on this topic as a Researcher for the Equal Justice Society.

${ }_{* * * * *}$ Associate Professor of Sociology, The College of New Jersey.

**** Wade H. McCree, Jr., Collegiate Professor of Law (Emeritus), University of Michigan. 


\section{EXECUTIVE SUMMARY}

Richard Sander's Stanford Law Review article, “A Systemic Analysis of Affirmative Action in American Law Schools," has generated considerable attention and criticism. This included a critical essay in the May 2005 Stanford Law Review by the four of us, as well as others in the same issue by Professors Ian Ayres and Richard Brooks, Michele Landis Dauber, and David Wilkins. Sander's “A Reply to Critics” also appeared in the same issue. For those following this empirical debate about the costs and benefits of affirmative action, we provide this working paper as a response to Sander's "A Reply to Critics." We show the weaknesses in the logic that underlies many of Sander's assumptions and arguments and show that his reply does not salvage the case against affirmative action that he claimed to have made in his Stanford article. Rather, Sander's reply explicitly or implicitly repudiates much of the methodology and many of the claims he made in "Systemic Analysis."

In Part II, we make the following general observations:

- The claims in Sander's A Reply to Critics are at odds with what he says in Systemic Analysis. The earlier article emphasized the effect of ending affirmative action on the number of African Americans who become lawyers (i.e., eventual bar exam pass rates). Sander's new arguments are centered on first-time bar passage rates, on the theory, with no supporting evidence, that this better reflects how much was learned in law school. Eventual bar pass rates are almost wholly ignored in A Reply to Critics, as they provide less support for his thesis.

- Sander now says that the impact ending affirmative action would have on the production of black lawyers was a peripheral issue in Systemic Analysis. This fundamentally mischaracterizes the thrust of his article, which repeatedly builds to the (incorrect) conclusion that ending affirmative action would increase the number of black law students who become lawyers. It is fair to say that without explicitly saying so, Sander has abandoned that part of his analysis.

- Contrary to Sander's latest claims, his findings in Systemic Analysis have not been meaningfully replicated. Attempts at replication, by ourselves and others, show that his earlier analysis was flawed and his findings do not hold.

Part III includes the following point-by-point response to Sander’s Reply:

- Sander claims that about $90 \%$ of the average black-white gap in law school grades is caused by affirmative action admission policies. This is wrong. Neither Sander nor anyone else has been able to explain more than a relatively small fraction of the variance in the grades law students receive.

o Within Sander's own data set of twenty law schools, LSAT and college GPA explain only $14 \%$ of individual differences in law school grades. 
Race and gender explain $6 \%$ of the variance, leaving $80 \%$ of the variance attributable to unknown or unmeasured factors.

o Social science norms caution against single cause, "magic bullet" explanations of between-group differences. In his article and reply, Sander uses flawed logic similar to that in some attention-grabbing studies of the cause of group differences in IQ and repudiated by scholars from across the political spectrum.

o Even if Sander's statement about affirmative action explaining 90\% of black-white differences is understood to be a hypothetical prediction rather than a true causal claim, there are still several problems with his claim.

- Sander's claim that it takes a theory to beat a theory ignores the fact that he has not offered a theory with sufficient prima facie support to even tentatively occupy the explanatory high ground. His claim that no critic has even entered the arena with a competing theory of the cause of black-white differences in graduation and bar passage rates is wrong.

o Sander hardly has a theory. What he has is a series of empirical results and an explanation for them, but since his empirical analyses are poorly executed, no theory can be grounded in their explanation. Much of the story, as Sander's own analyses reveal, is that as a group blacks enter law school with index credentials that are considerably below those of whites as a group. These initial differences are reflected in differences in the grades that whites and blacks receive and in the rates at which they graduate and pass the bar exam. One does not need a mismatch or other elaborate theory to explain performance differences. At the same time, it is important not to lose sight of the fact that large numbers of black law school students graduate, pass the bar and go on to have successful careers. The great majority of these successful students are in law schools with affirmative action admissions. The number of black students graduating and passing the bar would, as we showed in our reply to Systemic Analysis, be considerably lower in most years if affirmative action were to end.

o Others have identified a direct effect of race on first-semester law school grades, suggesting that index scores are not the whole story. One of us (Clydesdale) in a piece published before Sander's article, using the Bar Passage database, concluded that law school atmosphere plays a role in explaining the gap. An additional and substantial body of work, though not focusing on law students, suggests that stereotype threat may also help explain the poor test performance of black law students.

- The three-step argument that Sander offers to support his argument against affirmative action -- (1) LSAT and UGPA are important in explaining first-year law school grades; (2) Grades are important in explaining bar passage; and (3) Therefore, affirmative action harms African Americans by putting many in law 
schools where their LSATs and UGPAs will cause them to receive low grades and fail the bar exam -- is empirically and logically flawed.

o Sander confuses correlation with causation, meaning that the third step of his analysis does not necessarily follow from the first two. The claim that grades explain bar passage sounds like a causal claim but is instead a statistical one. What it means is that there is an association between grades and bar passage such that, on average, the higher one's grades the more likely he is to pass the bar. It does not mean that a $\mathrm{C}+$ student in a highly competitive school with a stiff curve would see his chances of passing the bar rise if he transferred to a weakly competitive school where the curve was such that he secured a $\mathrm{B}+$ average. That would happen only if the weaker school in some way better prepared the student to pass the bar, and the evidence does not indicate that this regularly occurs.

o The new data Sander presents in his reply (Table 1) fail to support the causation claim. No matter where a student ranks in his class, that student's chance of passing the bar is the same or higher than it would be had he attended a less selective institution. Assuming that similar grade point averages lead to similar ranks in schools at different levels of selectivity, these data show that the implications of grade level for bar passage vary with the quality of the school attended.

- Sander defended Systemic Analysis against our (and Ayres and Brooks') criticism that he used an unsound test of the mismatch hypothesis when he compared African Americans to whites with similar index scores. Sander counters that an alternative test - comparing black students to other black students with similar index scores who attend different tiers of law schools - is inferior due to selection bias. Selection bias refers to the following pattern: holding index credentials constant, the more selective the school that admits that student the more likely it is that the student has strengths not revealed in his index (e.g., stronger letters of recommendation, a more difficult college major, etc.).

Sander now correctly perceives selection bias as a problem, though it was scarcely mentioned in Systemic Analysis, for Sander is almost certainly right that law schools choose whom to admit based on both index credentials and other factors. Sander does not, however, recognize the inconsistency between this current claim and other strongly assertions in his original article, nor does he recognize that his new analysis is itself vulnerable to strong selection artifacts.

o We welcome Sander's recognition that the causal analyses he presents in Systemic Analysis are flawed because they do not take into account selection bias.

o Sander claimed in Systemic Analysis that law school admissions decisions were determined almost entirely by LSAT scores and UGPAs. If this were true, the selection bias that Sander identifies in his Reply (as a problem so serious that new analytic methods were required) would not be a problem at all because the variables that explained almost everything that can be explained about law school admissions would be in his model. Thus, though he does not say so, Sander has himself effectively refuted his 
earlier claim that he has "been unable to find a single law school in the United States whose admissions process operates in the way Justice O’Connor describes in Grutter." (Sander means by this to deny that any law school seriously considered factors other than LSAT and UGPA; if this were the case Sander could not make the selection bias claim he does.)

o Drawing on the research of Ayres and Brooks, Sander believes he can correct for selection bias by looking at students who chose to attend their "second-choice" law school, and that if he finds these students did better than those who attended their first-choice law schools he has evidence for his mismatch hypothesis unaffected by selection bias. In so claiming, he (and Ayres and Brooks) ignore the fact that some students attend secondchoice schools because they are offered attractive financial aid packages or are otherwise specially wooed. In offering students special financial aid packages, schools look at factors other than index scores. Thus, if students attending "second-choice" schools do better on the bar than those attending their first-choice schools, the difference can be due to selection bias. This is a particular threat to Sander's analysis because he tells us the effects he finds would be different if just twelve of the second-choice students in his sample had different bar results.

o Ayres and Brooks analysis of second-choice students is superior to Sander's analysis because they limited their analysis to blacks who were admitted to more than one law school and so had a choice to make. Their results do not support Sander's mismatch hypothesis. Ayres and Brooks' methods, like Sander's, do not control adequately for selection bias, but Ayres and Brooks' shortcoming strengthens their "no effect" conclusion since, to the extent selection bias exists, it favors the success of the second-choice students.

- Sander mistakenly persists in claiming that race-neutral admissions would almost entirely eliminate black-white gaps in LSATs and UGPAs within particular schools and so eliminate disparities in law school grades, graduation rates, and bar passage rates.

o Sander does not respond to our review of expert opinion from a range of disciplines on this point; he ignores UC system data on what happened when affirmative actions admissions were eliminated, and he infers conclusions from simulations that ignore his own concerns for selection bias by (unrealistically) positing that $80 \%$ to $90 \%$ of all law school admissions are based entirely on LSAT scores and UGPAs.

o Sander's analysis ignores the likely detrimental impacts of school atmosphere, stereotype vulnerability and substantial financial need on black learning, drop out and bar passage rates.

- Sander ignores the most recently available data in estimating the effects of ending affirmative action on the number of black lawyers. He continues to defend the use of 2001 rather than the 2004 data that we used in our estimates (or 2005 data that has since become available). 
o During years when total applicant volume was roughly 85,000 or higher (1991-1995 and 2002-2005), Sander's “grid model” indicates that ending affirmative action would have reduced African Americans admission offers from $19 \%$ to $53 \%$. When total applicant volume was under 80,000 (1996-2001) the expected number of admission offers to African Americans fell not nearly so much, from 9\% to 14\%. There is no reason to believe that 2001 is more typical of admissions volume than 2004, and when one engages in prediction he is usually attempting to predict for current circumstances. Moreover, rising numbers of college graduates suggest that if anything, law school applications will remain near the current high levels. Still the safest empirically based estimation is that the effects of ending affirmative action on the number of black law school students and the proportion of all law students who were black would vary considerably, ranging from relatively small (9-15\%) to so high that the dynamics of law school classes and the production of black attorneys would be severely impacted, (30-50\%).Many years, including the last few, are near the severe end of the scale.

o The 2005 data that just became available indicates, for example, that admission offers to African Americans would decline by $29.4 \%$ under the race-blind model endorsed by Sander, which is twice as large as Sander's estimate of a $14.1 \%$ decline using 2001 data.

- Sander presents no data to refute our claims about the particularly harmful effects of ending affirmative action on African Americans at elite law schools. Rather he dismisses our concern as a "slip into the apocalyptic school." "Apocalyptic" is lawyer's rhetoric, not a scientific argument. No doubt, Sander was reduced to rhetoric because he could not refute our empirical argument. Our concerns are serious ones.

o Sander's latest simulation projects, on his web site, suggest that without affirmative action Harvard and Yale may not admit any African Americans law students. These are the two law schools from which onequarter of all African American professors now teaching in U.S. law schools graduated.

- Without data bearing on the issue Sander speculates that because of the tightening of bar test standards first-time African American bar passage rates have dropped from 61\% in the BPS (1994-95 graduates) to about 33\% today. We believe both that Sander's gloomy speculation is off the mark and that while Sander has identified a serious issue ending affirmative action is no part of the solution; discontinuing affirmative action would only shrink further the production of black attorneys.

o Sander most likely has seriously overestimated the effect of tightening bar passage standards on blacks because in the BPS, the overall bar passage rate for blacks was brought down substantially by the low pass rates of those with LSAT/UGPA index scores in the 300s (17\%) and 400s (36\%). 
In the 2004 entering class, only one of every 27.8 enrolled black law students had index scores under 500. This is a significant improvement over the BPS cohort, when one of every 4.5 black law students had index scores below 500 . Similarly, $41.4 \%$ of the blacks in the BPS cohort had index scores above 600 , while $62.4 \%$ of the black law students entering in 2004 had index scores at this level. These improvements in the black admissions pool leads one to expect that with similarly difficult bar exams a much higher proportion of blacks would pass than passed 10 and more years ago, and it cautions against extrapolating from the BPS black bar passage rate to the likely bar passage rate of blacks taking today's bar exams.

o If the bar passage rates of blacks (and whites) has fallen due to more stringent test standards, the matter may be of concern, but ending affirmative action will do nothing to improve the situation. Instead we should be asking whether the newer tougher standards are justified because the prior standards failed to weed out many incompetent attorneys or whether the newer standards were based on inadequate information or, even worse, are a familiar example of a cartel working to limit competition. One of us (Kidder) has written on this issue.

\section{General Comments: The ART OF SANDER's RHETORIC}

In our empirical critique ${ }^{1}$ of Richard Sander's A Systemic Analysis of Affirmative Action in American Law Schools, ${ }^{2}$ we found much to criticize, and, as the reader will see below, we find much to criticize in his A Reply to Critics. ${ }^{3}$ Too often, we feel, Professor Sander's rhetorical skillsmake scientifically untenable claims sound plausible, especially for those who are unfamiliar with the data and methods of statistical analysis. We have looked at the data and know something about methods, so for scholars and policymakers following the ongoing debate, we provide this working paper which illuminates Professor Sander's wielding of numbers for rhetorical effect and his tendency to ignore a canon of good social science by not seeking to put his theories to the hardest possible test. We shall also show weaknesses in the logic that underlies certain of his assumptions and arguments. In addition, we shall show how his reply explicitly or implicitly repudiates much of the methodology and many of the claims he made in Systemic Analysis, while clinging firmly to its conclusion.

\section{A. “Mismatch” as a Moving Target: First-Time Versus Eventual Bar Pass Rates}

Before turning to the details of Professor Sander's reply, we wish to point to one rhetorical device that runs through most of Sander's new empirical analyses. Sander's new analysis differs from his earlier one in that he devotes his statistical attention almost

\footnotetext{
${ }^{1}$ David L. Chambers et al., The Real Impact of Ending Affirmative Action in American Law Schools: An Empirical Critique of Richard Sander's Study, 57 STAN. L. REV. 1855 (2005).

${ }^{2}$ Richard H. Sander, A Systemic Analysis of Affirmative Action in American Law Schools, 57 STAN. L. ReV. 367 (2004).

${ }^{3}$ Richard H. Sander, A Reply to Critics, 57 STAN. L. Rev. 1963 (2005).
} 
entirely to first-time bar passage rates and says barely a word about eventual bar passage, though the latter is key to whether a law school graduate joins the legal profession. This shift in focus, perhaps by capitalizing on random variation, makes it easier for Sander to claim that a mismatch effect exists and obscures differences between the results of his reanalysis and his original claims.

In Systemic Analysis, Sander considers both first-time and eventual bar passage rates as dependent variables and, if anything, emphasizes eventual pass rates because these most directly bear on his central claim in that piece that affirmative action most likely reduces the number of blacks entering the bar. ${ }^{4}$ In A Reply to Critics, the textual discussion virtually ignores eventual outcomes, although some tables present relevant data. We believe Sander does so because, as Ayres and Brooks show in their reanalysis of the bar passage data and as Ho also found, analyses using eventual bar passage as the test of affirmative action do not reveal a mismatch effect. ${ }^{5}$ Good science, which is not agenda driven, would highlight results with both dependent variables and the implications of the differences between would be an important point of discussion. Moreover, the difference has statistical implications. Since Sander might have claimed a success for his hypothesis had either first time or eventual bar passage rates indicated a mismatch effect, his claimed finding of a mismatch effect (which we show below is unreliable on several grounds) rests on significance tests that are inflated because they do not take account of Sander's ability to claim support for his hypothesis had either first time or eventual bar passage rates been correlated with his indicator of mismatch.

The claims in Sander's A Reply to Critics are so at odds with the claims of Systemic Analysis, that Sander's reply, as we shall show, effectively repudiates much of Systemic Analysis. In A Reply to Critics, unlike Systemic Analysis, the effect that mismatch has on the production of black lawyers is barely considered. Sander's new claim seems to be that first time bar passage rates are a better indicator than eventual bar passage of how much a student has learned in law school. Sander justifies this claim only by assertion, and doesn't comment on possible competing causes of passing on the second rather than the first attempt, such as random variation between two exam administrations, the failure of some on the economic margin to invest heavily in bar preparation courses before they have had one shot at the bar or whether first time bar passers have taken the test in easier jurisdictions than those who failed initial administrations. Moreover, even if passing the first time one takes the bar is an indication of having learned somewhat more, the difference between what first and second time passers have gained from their legal educations is likely to be small. The second time passers have, after all, passed an exam similar to that taken by the first time passers. What Sander lacks to support his hypothesis is information on how well first and eventual bar passers have scored on the exam. The absence of good data is, of course, not Sander's fault, but it is a mistake to try to draw strong conclusions from data that won't support such conclusions, especially in research intended to have policy relevance.

\footnotetext{
${ }^{4}$ See Sander, Systemic Analysis, supra note 2, at 444 tbl. 6.1, 448, 473 tbl. 8.2, 479.

${ }^{5}$ Ian Ayres \& Richard Brooks, Does Affirmative Action Reduce the Numbers of Black Lawyers?, 57 STAN. L. REv 1807, tbls. 1, 2A, 2B, figs. 2-3 (2005); Daniel E. Ho, Scholarship Comment, Why Affirmative Action Does Not Cause Black Students to Fail the Bar, 114 YALE L.J. 2005 (2005).
} 


\section{B. The Number of Black Lawyers: A “Side Issue”? (p. 1996)}

Sander's A Reply to Critics says that we are at our strongest when discussing the consequences of eliminating racial preferences on the production of black lawyers, but he then belittles the significance of our point by saying that "the consequences of eliminating racial preferences on the production of black lawyers" is "really a side issue in Systemic Analysis." ${ }^{6}$ In several public debates he has similarly claimed that the consequences of ending affirmative action were peripheral to what his article was written to show. In doing so, he fundamentally mischaracterizes his own article, and and as he does elsewhere in his reply; changes ground when the ground he currently stands on is shown to be indefensible. Language throughout Systemic Analysis makes it clear that Sander's assertion that there would be about as many if not more black lawyers if affirmative action were ended is a climax toward which the entire article builds.

On the first page of Systemic Analysis, Sander claims that, before him, no one has ever attempted a "comprehensive attempt to assess the costs and benefits of racial preferences in any field of higher education." 7 He then poses a series of questions, the very first of which is "What would have happened to minorities receiving racial preferences had the preferences not existed?" ${ }^{8}$ The introduction then previews his central finding that "in one realm after another the system of racial preferences . . . produces more harms than benefits for its intended beneficiaries."9 Which leads him to his capsule summary of his ultimate conclusion: "Perhaps most remarkably, a strong case can be made that in the legal education system as a whole, racial preferences end up producing fewer black lawyers each year than would be produced by a race-blind system." ${ }^{10} \mathrm{He}$ then repeats the point: "Under a series of plausible assumptions, race-blind admissions would produce an increase in the annual number of new black lawyers.”11

The body of the article mirrors the introduction. After relating the history of affirmative action in legal education, Sander in section after section sets forth his evidence that that, in one area after another - first law school grades, then law school graduation rates, then bar passage, then first jobs - affirmative action hurts rather than helps black students. All this builds to Part VIII, the final substantive section, titled "The Effects of Dropping or Modifying Racial Preferences,” where, in the article's concluding table, Sander sets forth his projection that ending affirmative action would lead to a 7.9 percent increase in the numbers of black lawyers entering the bar each year.

This is not the way one treats a "side issue".

\footnotetext{
${ }^{6}$ Richard H. Sander, A Reply to Critics, 57 STAN. L. REV. 1963, 1995 (2005).

${ }^{7}$ Sander, Systemic Analysis, supra note 2, at 368.

${ }^{8}$ Id.

${ }^{9}$ Id. at 371.

${ }^{10}$ Id. at 372 .

${ }^{11} \mathrm{Id}$.
} 


\title{
C. Revisionism About Part VIII of Systemic Analysis (p. 1999)
}

Sander's comments on our discussion of Part VIII, his summary section on the probable effects of ending affirmative action, are similarly revisionist. He writes:

\begin{abstract}
Most of the Chambers et al. critique does not focus on the mismatch theory, but on what would happen if all racial preferences were abolished....First, unlike the analyses in Parts II through VII of Systemic Analysis, which are all precise descriptions of how the current system operates and which I think no one has effectively challenged, I have never pretended that the projections in Part VIII of the paper are more than simulations and speculations about an unknowable future. ( $p$. 1999).
\end{abstract}

But Sander's introduction to Part VIII of Systemic Analysis does not suggest he is dealing with the "unknowable." He writes:

\begin{abstract}
In this Part (VIII) we will...attempt to answer a central question: what effect would the elimination or substantial modification of racial-preference policies have upon the number of practicing black lawyers? As we shall see, the paradoxical but straightforward answer is that the annual production of new black lawyers would probably increase if racial preferences were abolished tomorrow. (p. 468, boldface ours).
\end{abstract}

A few pages later Sander tells the reader that if his earlier empirical arguments are true, "then race-blind policies will moderately increase black graduation rates and will dramatically improve their performance on the bar.” (p.473).

he writes:

Sander is similarly not talking the language of simulation and speculation when

In the law school system as a whole, racial preferences no longer operate as a lifeline vital to preserve the tenuous foothold of blacks in the legal profession. Quite the contrary: racial preferences have the systematic effect of corroding black achievement and reducing the number of black lawyers. (p. 474-75).

Sander does admit that his simulation builds on some assumptions that should be considered more closely, but he later goes on to say:

Considering all the (admittedly imperfect) data in light of Table 8.2, I can see no reason for revising downward the table's estimate that the production of black lawyers would rise significantly in a world without racial preferences. (p.476).

Then, after rehearsing several objections that might be made to his simulation, and suggesting they are most likely not substantial, he concludes a trifle more modestly: "One can make an argument that the number might decline, but the balance of evidence suggests an increase is more likely." (p. 477). We have perhaps quoted Sander excessively on this point, but we want to make clear we are not quoting out of context with this example of how Sander changes positions regarding a key claim. We also want to make it clear to all that no matter how well it reads, Sander's confident assertions do not necessarily characterize accurately either his work or that of others. Further examples of this will follow. 


\section{Has Systemic Analysis been “thoroughly replicated”?}

Dauber takes me to task for saying on several occasions that the key analyses in my article have been replicated by other scholars. Here again Dauber stumbles upon an allegation that is so wrong that it seems more like comic irony than serious criticism. For I cannot think of any social science work ever published that has been so thoroughly replicated in such a short period of time. [Sander then explains his views on replication, which for him involve running the exact same analyses on the exact same data, and how parts of his article have been replicated by Ayres and Brooks, Lindgren, Johnson, Dinovitzer, and a law review editor]...Probably none of these individuals agrees with all of my methodological choices...But the statistics in Systemic Analysis, and the dimensions of the serious problems it documents, are accurate. (pp. 1984-86).

In January 2005 Sander was even more extreme in claiming on National Public Radio that "half a dozen social scientists that I know of have been working on replicating my analyses for the past three months, and so far, I haven't found anyone who has found a single mistake in the study." "12 We suspect that boldly stated claims like these have contributed to misperceptions, sometimes picked up by journalists, that the results of Systemic Analysis are strengthened by the work of other analysts. ${ }^{13}$ Except in the narrowest sense, this is not so. Instead, Sander obfuscates with rhetoric, this time playing on ambiguity in the word "replicated," and writing as if he is using the term in the sense that is conventional within science, when in fact he is not.

The Committee on Scientific Principles for Education Research, in the course of advocating greater replication of education research explains what it means by replication and points out that replication has both rudimentary and complex dimensions:

Replication and generalization strengthen and clarify the limits of scientific conjectures and theories. By replication we mean, at an elementary level, that if one investigator makes a set of observations, another investigator can make a similar set of observations under the same conditions. Replication in this sense comes close to what psychometricians call reliability-consistency of measurements from one observer to another, from one task to another parallel task, from one occasion to another occasion.... At a somewhat more complex level, replication means the ability to repeat an investigation in more than one setting (from one laboratory to another or from one field site to a similar field site) and reach similar conclusions. To be sure, replication in the physical sciences, especially with inanimate objects, is more easily achieved than in social

\footnotetext{
${ }^{12}$ Michele Landis Dauber, The Big Muddy, 57 StAn. L. Rev. 1899, 1909 n.56 (2005). We had by January of 2005 found numbers of mistakes in Sander's study and posted an analysis on the web, which Sander was well aware of, demonstrating numerous mistakes in his analysis, like his mistaken estimation of the impact of abolishing affirmative action on black law school enrollment described above. We had also shown mistakes in his interpretation of statistics and that his hypotheses did not survive other tests they might be put to. Professor Lindgren, whom Sander has cited as one of his replicators, had by the time Systemic Analysis was published informed Sander that he his failure to find a significant relationship in one of his data sets turned on a questionable coding decision, which we showed in our reply to be not just questionable but erroneous. Sander's remarks indicate that he does not consider Lindgren's failure to duplicate his results by correcting a coding error to be a failure to replicate because, we assume, Lindgren reached the same erroneous results Sander did when he ran the same equations with the same erroneous coding.

${ }^{13}$ See Terry Eastlund, The Mismatch Game, WeEkly STANDARD, Jan. 3, 2005 (Interviewing Sander and reporting "[O]ther academics working from [his] data sets were reaching the same conclusions as he.").
} 
science or education....The role of contextual factors and the lack of control that characterizes work in the social realm require a more nuanced notion of replication. ${ }^{14}$

Sander's notion of replication is simpler and less meaningful than even the elementary form of replication the Committee identifies. As Sander uses the term, replication involves little more than a check by others that no mistakes were made in applying a canned statistical program to a particular source of data. Sander's replication provides no check on mis-specified hypotheses, flawed methods or flawed or otherwise limited data. This is not, however, what most scientists mean when they say their work has been replicated. They mean that others using different data and/or the same data with different methods have reached essentially similar conclusions. It is only when replication has occurred in this sense that we can have significantly greater confidence in the validity and generalizability of one person's findings. Running the same regression models on the same data, whether done by the original researcher or by another, does almost nothing to increase our confidence in either. Neither Michelle Dauber nor any of Sander's other critics have ever accused Sander of being unable to replicate his findings in this unconventional, narrow sense, but it is only by confining the meaning of replication to this narrow sense that Sander is able to treat Dauber's criticism so dismissively. ${ }^{15}$

14 Committee on ScIENTIFIC PRINCIPLES FOR EDUCATION RESEARCh, ScIENTIFIC RESEARCH IN EDUCATION 70-71 (Richard J. Shavelson \& Lisa Towne, eds., 2002), available at http://print.nap.edu/pdf/0309082919/pdf_image/70.pdf.

${ }^{15}$ In A Reply to Critics Sander, in responding to the piece by Dauber, uses her criticism as an excuse to make irrelevant and misleading claims about the lack of data sharing by Lempert, Chambers and Adams:

Richard Lempert, David Chambers, and Terry Adams have been even more restrictive with the data they assembled for The River Runs Through Law School, their study of Michigan graduates. Their study was published in Law and Social Inquiry in 2000, and I was one of several academics asked by the journal to write a commentary on the work. When I asked Lempert at the time for a copy of the data, he told me that it was unavailable because of the ongoing litigation involving the University of Michigan's admissions procedures (without explaining why data disclosure would not be particularly vital if their findings were being presented to the courts). After the 2003 Supreme Court decisions in Grutter v. Bollinger and Gratz v. Bollinger, I renewed my request for the data. Eighteen months later, after multiple negotiations and missed deadlines, I began to receive the data-but too late to incorporate into this Reply.

Sander's story is misleading on a number of points. A request was made of Lempert (who did not have custody of the data) for the River Runs Through Law School data during the course of the Grutter litigation, and Sander was told that the ongoing litigation precluded its release. This request was not renewed according to our recollection until the summer of 2004, when another informal request was made. However, the request was somewhat confused, and it was not clear whether Sander wanted the River Runs Through Law School data or the Michigan alumni data set which has many similarities with the other data set and has been made available to several researchers over the years. At that time Sander was told by Terry Adams, the custodian of the data, that he had to make a formal request for the data and that we would have to prepare it for distribution, something that had not been done because the more or less equivalent alumni data set was available for distribution and no one to that point, except Sander during Grutter, had ever asked for these data.

Sander did not, in fact, make a formal request for the River Runs Through Law School data until November 2004, and preparing the data for release to him began prior to his formal request. However, it was a lengthy process. Because the data pertain to one school's alumni and only a limited number of black students had attended Michigan over the years, re-identification of many respondents, especially minority 
The late Stephen J. Gould argued, "Replication with difference, builds the best case for generality-for how can we prove a coordinating hypothesis unless we can apply it to multiple cases?" 16 That is, replication studies that also vary conditions help to answer the essential question of whether or not a claim is robust. Gould's ideal involves replicating research in different contexts to see if the same relationships hold. For most purposes Sander's results are not amenable to this kind of replication, for all investigators of minority and white law school performance must use the same data set. We cannot for example, learn through replication whether Sander's models would yield different results if applied to the 2001 rather than the 1991 entering law school cohort, for we have no bar exam data by race for the 2001 cohort. But another form of replication with a difference involves using different methods or tests to ascertain what relationships exist in the data. If results do not replicate with different models, there is reason to suspect them and a need to closely examine the different models and ascertain which is the most plausible. If results do replicate using a range of different plausible models, one can be reasonably confident that the relationships found exist in the data, though there is no guarantee that similar relationships would exist had different data been examined.

We and others, including Ayres and Brooks and Daniel Ho, have attempted to replicate Sander's results using different analytic approaches. Unlike those who simply reran his analyses, we and others whom we cite find that Sander's results, when put to more adequate tests, are not replicated. No one to our knowledge has published a statement saying that they have attempted to replicate Sander's analysis using different methods and can confirm his conclusions. Below are the conclusions reached by those who have published the results of their attempts at replication:

1. Ayres and Brooks, who assumed for purposes of replication that Sander's admission and enrollment estimates were valid, concluded, "[W]e found no compelling evidence that the system of affirmative action in place in 1991 reduced the number of black lawyers." (p.1853)

2. Our analysis examined Sander's claim that, holding index scores constant, students would be more likely to pass the bar if they attended lower prestige law schools, and we found it was not true. Applying Sander's own methods but using data for the 2004 admissions cycle rather than the 1991 cycle, we found that without affirmative action the number of African Americans joining the legal profession would diminish by $21 \%$ whereas Sander, using 2001 data, predicted a rise of about $8 \%$. Using different and, we believe, more realistic assumptions than those Sander used, we found that even using the 2001 data ending affirmative action would be accompanied by a marked drop rather than an increase in the number of black lawyers produced (and a 30\%-40\% decline in

respondents, could have been easily accomplished. In order to ethically release the data, given promises of confidentiality made to survey respondents, the data had to be masked in certain ways. In fact Terry Adams devoted scores of hours to this enterprise at the Law School's expense, and the data was given to Sander as soon as it was ready for release. Sander knows these details. He chose to ignore them.

${ }^{16}$ Stephen J. Gould, I Have Landed: The End of A Beginning in NATURAl History 246 (2002). See also Barbara Schneider, Building a Scientific Community: The Need for Replication, 106 TEACHERS COLLEGE RECORD 1471, 1473 (2004) ("Without convergence of results from multiple studies, the objectivity, neutrality, and generalizability of research is questionable.”). 
2004). We accompanied these failures to replicate Sander's results with detailed explanations of why statistical flaws in Sander's work and his use of unrealistic assumptions made the non-replicability of his results unsurprising.

3. Daniel Ho, in the Yale Law Journal, used the same LSAC Bar Passage Study data that Sander did and more sophisticated statistical methods to assess Sander's thesis and found, "In short, whichever way one cuts it, there is no evidence for the hypothesis that law school tier causes black students to fail the bar." 17

4. Economists Jesse Rothstein of Princeton University and Albert Yoon of Northwestern University School of Law, using the BPS, conclude, "We find little support for claims that mismatch is an important consequence of affirmative action in law school admissions. We reject large mismatch effects on bar passage rates for all but the least qualified law school students." 18

Sander's claims of replication are thus deeply misleading. They certainly do not support his assertion that "the statistics in Systemic Analysis, and the dimensions of the serious problems it documents, are accurate.” (p.1986). Serious attempts to replicate Sander's results using more adequate methods and more realistic assumptions suggest the opposite is true.

\title{
III. SPECIFIC COMMENTS
}

\section{A. Arguments on the Mismatch Effect (pages 1968, 1996-98)}

\section{1) LSAT \& UGPA Explain 90\% of Differences?}

Sander's A Reply to Critics criticizes us (as well as Ayres and Brooks) for rejecting his claim that index score differences explain $90 \%$ or more of black-white differences in law school grades:

\begin{abstract}
Any of these formulations show that differences in background credentials explain nearly all of the differences in black-white performance at law school; the debate is whether the credentials gap explains 85\%, 95\%, or 100\% of the gap. A much larger study that I discovered after Systemic Analysis went to press found "very slight" underperformance by blacks (when controlling for preferences), measuring it at about one-eighth of a standard deviation [citing Anthony \& Liu 2003]. I accept that figure as the best available estimate, and conclude that black underperformance could account for as much as 6-10\% of the black-white difference in grades. This suggests that $90-94 \%$ of the black-white gap in law school grades is due to differences in entering credentials--and nearly all of that gap is due to racial preferences in admissions. ( $p$. 1968)
\end{abstract}

Like his claim that affirmative action reduces the number of black lawyers, the assertion in A Reply to Critics that affirmative action explains about $90 \%$ of the gap in law school grades (p. 1996) has a certain shock value but is fundamentally mistaken and misleading.

\footnotetext{
${ }^{17}$ Daniel E. Ho, Scholarship Comment: Why Affirmative Action Does Not Cause Black Students To Fail the Bar, 114 Yale L.J. 1997, 2004 (2005).

18 Jesse Rothstein \& Albert Yoon, Mismatch in Law School, at 30 (Jan. 2006), working paper available at http://ist-socrates.berkeley.edu/ raphael/IGERT/Workshop/rothstein_yoon_jan180611.pdf
} 
In this section we respond to Sander's claim on two levels. First by using social science terms with well understood conventional meanings (e.g. "explains" and "is due to" next to percentages that seem to express $R$-square values ${ }^{19}$ ) Sander invites readers to conclude that LSAT and UGPA disparities are the overwhelming cause of the blackwhite gap in law school grades. We show why this is not so. Second, we show that if Sander's statement is read correctly, not as a causal claim but as a hypothetical argument about what would happen in the absence of a gap in LSATs and UGPAs, it is similarly unpersuasive, for it rests on flawed reasoning.

In claiming that "background credentials explain nearly all of the differences in black-white performance at law school” (p.1968) Sander uses the term "explain” loosely, and ignores social science norms, which caution against making overreaching claims about causation. ${ }^{20}$ These professional norms explain, for example, scientific reaction to The Bell Curve. While there is a consensus that "heritability" $\left(h^{2}\right)$ explains a majority of differences in intelligence among individuals, ${ }^{21}$ there is an equally strong consensus rejecting, on scientific grounds, Hernstein and Murray's provocative corollary arguments in The Bell Curve ${ }^{22}$ that black-white group differences in IQ are primarily genetic and that these inherited differences largely explain black-white differences in wages and other key indicators of social position. ${ }^{23}$

\footnotetext{
${ }^{19}$ See e.g., G. David Garson, Logistic Regression, at http://www2.chass.ncsu.edu/garson/pa765/logistic.htm (“[A]n R ${ }^{2}$ measure seeks to make a statement about the 'percent of variance explained'...”); Daniel L. Rubinfeld, Reference Guide on Multiple Regression, in REFERENCE GUIDE ON SCIENTIFIC EVIDENCE at 179, 225 (Fed. Judicial Ctr. ed., 2d ed. 2000) available at http://www.fjc.gov (defining $R$-square as "a statistic that measures the percentage of the variation in the dependent variable that is accounted for by all of the explanatory variables in a regression model.”).

${ }^{20}$ See e.g., Am. Psychol. Ass'n Task Force on Statistical Inference, Statistical Methods in Psychology Journals: Guidelines and Explanations, 54 AM. PsYchOL. 594, 600 (1999) (The APA offers the following guidance on causation: "Inferring causality from nonrandomized designs is a risky enterprise. Researchers using nonrandomized designs have an extra obligation to explain the logic behind covariates included in their designs and to alert the reader to plausible rival hypotheses that might explain their results. Even in randomized experiments, attributing causal effects to any one aspect of the treatment condition requires support from additional experimentation.”). See also Paul W. Holland, Statistics and Causal Inference, 81 J. AM. STATISTICAL Ass'N. 945 (1986).

${ }^{21}$ Ulric Neisser et al., Intelligence: Knowns and Unknowns, 51 AM. Psychol. 77, 85 (1996).

${ }^{22}$ Richard J. HERRNSTEIN \& CHARLES MuRRAY, THE Bell CuRve 298-99 (1994).

${ }^{23}$ See e.g., James J. Heckman, Lessons from the Bell Curve, 103 J. PolitiCAL ECON. 1091, 1106-07 (1995) ("[N]either $g$ nor AFQT [Armed Forces Qualifying Test] explains all that much of the variance in log wages. The highest $R^{2}$ is less than 22 percent. A lot of variability in log wages remains unexplained.”); id at 1099 ("Heritability calculations tell us nothing about the contribution of the environment to betweengroup differences....”); John CAWley et AL., MEASURing the EFFeCTS OF Cognitive ABILITY, NBER Working Paper No. 5645, p. 12 (July 1996) (arguing that their data from the National Longitudinal Survey of Youth (NLSY), which under the most favorable assumptions explain a third of wage variation, "conflict with the model of cognitive determinism implicit in Hernnstein and Murray.”); William T. Dickens \& James R. Flynn, Heritability Estimates Versus Large Environmental Effects: The IQ Paradox Resolved, 108 Psychol. Rev. 346 (2001); Claude S. Fischer et AL., INEQUAlity by DESIGN: CRACKING THE Bell CuRve MYTH 14-15, Chap. 8 (1996); Ned Block, How Heritability Misleads About Race, 56 CogNITION 99 (1995); Richard C. Lewontin, Race and Intelligence, 26 SCIENCE AND PUBliC AfFAIRS: BulLETIN OF THE ATOMIC SCIENTISTS, March 1970, at 2, 7-8 (illustrative example involving plants where $100 \%$ of individual level differences in height are genetic but $100 \%$ of between-group differences in height are explained by
} 
There is irony in Sander's criticism of Ayres and Brooks for failing to appreciate the distinction between individual and group-based predictions of law school performance. $^{24}$ Systemic Analysis is frustratingly vague about the implications of this very distinction, and Sander plays on this vagueness in writing as if he has proved causation when he cannot. The empirical data in Systemic Analysis related to individual characteristics, and despite Sander's protestations to the contrary Ayres and Brooks were right in claiming that Sander drew conclusions about the role of affirmative action for African Americans as a group from that individual-level data. ${ }^{25}$

One reason Sander's evidence does not establish affirmative action as the overwhelming cause of black-white grade disparities is that grades are given within schools, and current research leaves much of what leads to grade variation within schools unexplained. For example, Sander's 1995 NSLSP dataset illustrates how little we know about the causes of graded law school performance, even in the first semester. With

the environment); Stephen J. Gould, Curveball, in The Bell CuRve WARS 11, 13 (Steven Frazer ed., 1995).

${ }^{24}$ In A Reply to Critics, Sander writes of Ayres and Brooks:

Their style of argument relies instead on making claims of the form, "If Sander is right, then $X$ must be true. Since $X$ is not true, Sander is wrong." The problem is that none of their "then $X$ must be true" statements follows from my article. For example:

(1) Ayres and Brooks write:

An ... audacious claim of Sander is that, after controlling for a student's relative entering credentials, the probability at the moment of entering law school that a student will become a lawyer is not importantly determined by the student's race or any other factors. Sander's argument seems to be that if you know a student's LSAT and undergraduate GPA relative to those of her classmates at the moment she enters law school, you can make the best prediction possible (at that point) about her chances of ultimately graduating and becoming a lawyer.

Such a claim would indeed be audacious-and wrong-but I never make it. Indeed, Systemic Analysis presents a variety of data showing that these credentials leave a great deal of variation in law school and bar performance unexplained. (pp.1986-87).

25 The following quotes in Systemic Analysis are illustrative of why we believe Ayres and Brooks drew reasonable conclusions about Sander's study, which was, after all, based on the analysis of individual level data:

- "In other words the collectively poor performance of black students at elite schools does not seem to be due to their being "black" (or any other individual characteristic, like weaker educational background, that might be correlated with race). The poor performance seems simply to be a function of disparate entering credentials......" (p. 429).

- "Law school GPA is by far the principal determinant of whether a student in the LSAC-BPS study failed to graduate. School eliteness is a relevant factor, but it is overshadowed by the importance of academic performance. Part-time status is important but affects a relatively small proportion of students; higher family income appears to play a marginal but measurable role. Race is irrelevant or nearly so.... [which] implies that there is no correlate of race (e.g. discrimination) that causes blacks to drop out at disproportionate rates.” (p.439).

- "If we know someone's law school grades, we can make a very good guess at how easily she will pass the bar. If we also know her LSAT score, her undergraduate GPA, and the eliteness of her law school, we can do even better.....But knowing someone's race seems irrelevant.” (pp. 444-45).

It certainly appears from these quotes that Sander is predicting individual rather than group behavior and the factors that he mentions in his reply - study habits and reasons for attending law school - are not mentioned in Systemic Analysis. 
unreported race included as a dummy, along with LSAT, UGPA, gender, and the other race dummies, the $R^{2}$ is $.199 .^{26}$ That means $80.1 \%$ of the variance in first semester law school grades is not explained by the model. ${ }^{27}$ Step-wise regression indicates that gender and race by themselves explain just 5.9\% of the variance in first semester grades. Adding LSAT scores and UGPA improves the explanatory power of the model by 14 percent.

If entering credentials only explain one-sixth of the variance in the grades that black or white students in a given school receive or in the grades all a school's students receive, LSATs and UGPAs cannot explain, in any causal sense, anything close to ninetenths of the gap between the grades of black and white students in any given school. To suggest that we know the entire grade difference story, and that $90 \%$ of it has to do with index scores and affirmative action is scientifically untenable even if it is not intentionally misleading. This big picture is obfuscated in Sander's A Reply to Critics.

The data that inform this picture are displayed in Table 1 below. $^{28}$

\section{Table 1: Factors Associated with First-Semester Law School GPA, Comparing Sander's Model with Alternative Models ${ }^{29}$}

\begin{tabular}{|c|c|c|c|c|c|c|}
\hline \multirow[b]{2}{*}{ Independent Variable } & \multicolumn{2}{|c|}{$\begin{array}{c}\text { Sander's Table } 5.2 \\
\text { results }\end{array}$} & \multicolumn{2}{|c|}{$\begin{array}{l}\text { Corrected Model 1, } \\
\text { separately identifying } \\
\text { non-reported race with } \\
\text { dummy variable }\end{array}$} & \multicolumn{2}{|c|}{$\begin{array}{l}\text { Corrected Model 1a, } \\
\text { separately identifying } \\
\text { non-reported race with } \\
\text { dummy variable \& } \\
\text { evaluating weighted } \\
\text { LSATs \& UGPAs }\end{array}$} \\
\hline & Std Coef. & t-statistic & Std Coef. & t-statistic & Std Coef. & t-statistic \\
\hline $\begin{array}{l}\text { ZLSAT (standardized to } \\
\text { law school) }\end{array}$ & $0.385 * * *$ & 25.975 & $.365 * * *$ & 24.463 & & \\
\hline $\begin{array}{l}\text { ZUGPA (standardized } \\
\text { to law school) }\end{array}$ & $0.212 * * *$ & 14.915 & $.202 * * *$ & 14.171 & & \\
\hline
\end{tabular}

${ }^{26}$ As we note on the next page (and in our Stanford Law Review critique), results change in some significant ways when one does not make Sander's mistake of coding as white all students who did not report their race. This is why we use a dummy code for students who did not provide race information.

27 Similarly, LSAC's validity studies indicate that academic index scores explain about $25 \%$ of variance in first-year law school grades within ABA law schools, which is higher than Sander's NSLSP dataset of firstsemester grades, but still modest. LiSA A. ANTHONy ET AL., LAW SCH. AdMission CounCIL, PREDICTIVE VALIDITY OF THE LSAT: A NATIONAL SUMMARY OF THE 1995-96 CORRELATION STUDIES 6 tbl.2 (1999); Linda F. Wightman, The Threat to Diversity in Legal Education: An Empirical Analysis of the Consequences of Abandoning Race as a Factor in Law School Admission Decisions, 72 N.Y.U. L. REV. 1, 31-34 (1997).

Imperfect correlation between predictors and criterion variables is due to a several factors, including unexplained variance as well as range restriction and measurement error. However, since Sander's claims refer to enrolled law students, arguments about restriction of range cannot rescue his claim. ${ }^{28}$ This revises and can be compared with Table 2 in our Stanford Law Review essay (p. 1880).

${ }^{29}$ To construct Model 1a, we obtained the median LSAT scores for each of the 21 law schools in Sander's NSLSP, and used them to reverse his law school-standardized LSAT scores into nationally-standardized LSAT scores. We did the same for UGPAs, weighting UGPAs by law school rank. We then re-ran the regressions using nationally-standardized LSAT scores, UGPAs, race and gender. Despite Sander's emphasis on the importance of using nationally standardized scores, we obtained, as the table reveals, virtually identical results. Sander's standardization of LSATs and UGPAs by law school has negligible effects on their predictive power (see revised Table 1). 


\begin{tabular}{|l|c|c|c|c|c|c|}
\hline $\begin{array}{l}\text { ZLSAT (weighted by } \\
\text { median law school } \\
\text { LSAT score) }\end{array}$ & & & & & $.359^{* * *}$ & 23.890 \\
\hline $\begin{array}{l}\text { ZUGPA (weighted by } \\
\text { law school rank) }\end{array}$ & & & & & $.174^{* * *}$ & 12.099 \\
\hline Male & .018 & 1.289 & .020 & 1.454 & .015 & 1.085 \\
\hline Asian & -.007 & -.516 & $-.025 \dagger$ & -1.747 & $-.028^{*}$ & -1.979 \\
\hline Black & -.007 & -.480 & $-.030^{*}$ & -1.996 & $-.037^{*}$ & -2.469 \\
\hline Hispanic & -.011 & -.793 & $-.029^{*}$ & -2.010 & $-.030^{*}$ & -2.048 \\
\hline Other (Reported ${ }^{1}$ ) Race & -.021 & -1.489 & $-.040^{* *}$ & -2.816 & $-.042^{* *}$ & -2.987 \\
\hline Race Not Reported & $\begin{array}{l}\text { Neither excluded nor } \\
\text { separately identified }\end{array}$ & $-.103^{* * *}$ & 7.055 & $-.106^{* * *}$ & 7.207 \\
\hline Model N & \multicolumn{2}{|c|}{$\mathrm{N}=4,257$} & \multicolumn{2}{|c|}{$\mathrm{N}=4,257$} & \multicolumn{2}{c|}{$\mathrm{N}=4,257$} \\
\hline Adjusted R-square & \multicolumn{2}{|c|}{$\mathbf{. 1 9 0}$} & \multicolumn{2}{|c|}{$\mathbf{1 9 9}$} & \multicolumn{2}{|c|}{} \\
\hline
\end{tabular}

Source: National Survey of Law School Performance (Sander, 1995)

Thus Sander's own data set and his own analysis make it clear how little we know about a student's likely performance when all we know is the students LSAT score and UGPA. ${ }^{30}$

Many black students attend schools that would not admit them but for affirmative action, and, as Sander tells us, students with index scores at a given level tend to do better in terms of grades if they attend less selective institutions, but the tendency is much less pronounced than Sander's 90\% figure would suggest. More importantly, however, this tendency, as we showed in our response to Systemic Analysis (pp. 1882-86) and as the articles by Ayres and Brooks and Ho indicate, does not translate into greater or lesser success in eventual bar passage. ${ }^{31}$

We mentioned at the start of this section that although Sander appears to be making a strong claim about proven causation, he is at most making a hypothetical argument about what would happen in the absence of a black-white gap in LSATs and UGPAs. $^{32}$ As we understand it, the argument is rooted in the premise that group differences are ordinarily more amenable to prediction than differences between individuals. $^{33}$ That reliability increases with sample size is true enough, but the rest of Sander's claim does not follow from this fact. For one thing, Sander has not rigorously

\footnotetext{
${ }^{30}$ The reader should also note that contrary to claims Sander made in Systemic Analysis, when a coding error he made is corrected not only is being black significantly associated with receiving lower grades even with the index variables in the model, but being of any minority race has a similar association. We do not want to make too much of this, for the impact of minority status alone is small but the results hint at the possibility that something about the atmosphere of, or the tests given in, law schools favors white students. Sander acknowledged the coding error and its effect in a footnote in Systemic Analysis, but treated it as if it were just an alternative way of looking at the data and did not change the substance of his textual claims or the table presenting the data.

${ }^{31}$ Ayres \& Brooks, supra note _ at 1817-27; Ho, Why Affirmative Action Does Not Cause Black Students To Fail the Bar, supra note _ at 2003 fig. 1.

${ }^{32}$ This interpretation of what Sander is doing reflects our understanding of Sander's somewhat vague replies to e-mails asking him what he meant when he claimed that "background credentials explain nearly all of the differences in black-white performance at law school.” (p.1968).

${ }^{33}$ See Sander, A Reply to Critics, supra note 3, at 1986-87; Sander, Systemic Analysis, supra note 2, at 423 n.159.
} 
established that the sources of individual-level differences and the sources of black-white group-level differences in law school grades and bar passage results are in fact identical. $^{34}$ There is reason to believe they are not. Referring back to Table 1, step-wise regression indicates, as we have noted, that race and gender explain 5.9\% of the variance in the first term grades received by students at the 21 schools in Sander's 1995 sample. Adding LSAT score and UGPA raises the explained variance by $14 \%$, resulting in a model that explains $19.9 \%$ of the variance.

Sander's response in A Reply to Critics to the fact that race does seem to affect an individual's grades is to backtrack a bit from his original claim and acknowledge, based on research by Anthony and Liu, a small role for race at the group level (i.e., overprediction). He then declares victory by proclaiming that "the debate is whether the credentials gap explains $85 \%$, 95\%, or $100 \%$ of the gap.” (p.1968). But if Sander were accurately characterizing what overprediction studies "show" with respect to the role of academic index scores, one should consistently find evidence of this in the primary literature on the topic - in the 2003 LSAC study by Anthony and Liu (cited by Sander) and in the other large multi-institution studies of differential prediction conducted by LSAC, ETS, the College Board, etc. In fact, to our knowledge none of these studies claim that academic credentials explain nearly all the black-white gap in grades. ${ }^{35}$ Moreover, Sander's approach to Anthony and Liu's work is particularly misguided because the black-white gap in grades is not the dependent variable in their models, so their study cannot explain it, nor does anything about their models attribute grade differences to affirmative action (i.e., Sander is wrong in suggesting that Anthony and Liu are "controlling for preferences"). In earlier work Sander highlights the modest correlation between academic index scores and law school grades. ${ }^{36}$ We do not understand why he gives them such power now.

\footnotetext{
${ }^{34}$ See Lewontin, supra note

${ }^{35}$ See e.g., Lisa C. ANTHONY \& Mei Liu, LaW Sch. Admission Council, Analysis of Differential Prediction of Law School Performance by Racial/Ethnic Subgroups Based on the 1996-1998 Entering LaW School Classes (2003); Linda F. Wightman \& David G. Muller, An ANAlysis of DifFERENTIAL VALidity and DifFERENTIAL PREDICTION FOR BLACK, MEXICAN AMERICAN, HisPaNiC AND White Law School Students (1990); John Young \& Jennifer L. Kobrin, Differential Validity, Differential Prediction, ANd College Admission Testing: A Comprehensive Review AND ANALYSIS, College Board Research Report No. 2001-6 (2001); Frederick E. Vars \& William G. Bowen, Scholastic Aptitude Test Scores, Race, and Academic Performance in Selective Colleges and Universities, in The Black-White Test Score GAP 457, 475-76 (Christopher Jencks \& Meredith Phillips eds., 1998) (finding significant overprediction at College and Beyond institutions, but cautioning: "Taken together, these [SAT scores and other] variables account for only about a quarter of the variance in academic performance - a result common to almost all models of individual behavior. Clearly, much remains to be explained. The relatively weak relationship between SAT scores and academic performance, especially for black students, underscores why admission officers must be free to consider factors other than grades and SATs when choosing among candidates. The large amount of unexplained variance also cautions against drawing more than tentative conclusions about relative importance of precollege versus college effects on performance.”). See also Robert L. Linn, Admissions Testing: Recommended Uses, Validity, Differential Prediction, and Coaching, 3 APPLIED MEASUREMENT IN EDUC. 297 (1990).

The exception is Klitgaard, who in reviewing studies done by others, adopts a mistaken approach that mirrors Sander. RoBert KLITGAARD, CHOOSING Elites 162-63 (1985).

${ }^{36}$ Kristine S. Knaplund \& Richard H. Sander, The Art and Science of Academic Support, 45 J. LEgAL EDUC. 157, 213 (1995) (In the appendix authored separately by Sander: "It is worth noting that the LSAT
} 
There are other problems with Sander's argument about what would happen in his hypothetical world where the abolition of affirmative action negated differences between the credentials of white and black students. One cannot directly generalize from the overprediction studies by Anthony and Liu and others because none of this research addresses the counter-factual scenario of a world without affirmative action, where admissions processes would reshuffle students to different law schools, and could change both the degree of overprediction and the predictive validity of LSATs and UGPAs (i.e., range restriction could lessen the predictive utility of index scores and other factors, including race, could then explain more of the gaps that remained). In addition, we believe that Sander substantially underestimates the likely size of a post-affirmative action credential gap (see Section III.B.1), and, perhaps more importantly, in his Reply he presents no evidence that shunting black law students to less prestigious schools would increase the rate at which these students graduate and become lawyers, for he chooses to focus only on first time bar passage rates.

Sander's argument for a hypothetical world, cannot substitute for empirical proof, which is what the real debate should be about. But for those who like hypotheticals, here is another one. Suppose we could magically give all the law students in Sander's NSLSP dataset identical LSAT scores and college grades; $80 \%$ of the differences in firstsemester law school grades would remain. ${ }^{37}$ Moreover, since we would not have leveled the causes, or even the correlates, of most of what affected students grades, large differences in the performance of blacks as a group and whites as a group would remain. But by definition there would be zero academic index score disparities among individuals, so one could not attribute black-white group differences in law school performance to affirmative action, much less treat affirmative action as an overwhelming cause. The reader shouldn't put too much stock in this hypothetical either. Rather the reader should ask social scientists what the facts show. The facts do not show that affirmative action, or even different index credentials, explain all but 15, 10 or 5 percent of the variance between the grades that white and black students receive. The data do suggest that index credentials and their correlates explain part of this difference and that race and its correlates explain another part. But when it comes to understanding why white student A receives higher grades than black student B, what we can't explain far exceeds what we know.

\section{2. $\quad$ Sander's Theory Versus Alternatives like "Stereotype Threat” and Law School Atmosphere}

None of these contributors offers any alternative explanation of this staggering black-white gap in graduation and bar passage, let alone a strategy for addressing it. If Stigler is right that it takes a theory to beat a theory, no one has even entered the arena. (p.1965)

and admissions index combined probably do a much poorer job of predicting second-semester GPA than does first-semester GPA; although indices like the LSAT are the best measures available for predicting law school performance before law school begins, they aren't very strong predictors.”) (emphasis in original).

${ }^{37}$ FISCHER ET AL., supra note _ at 14-15 (making a similar argument about test scores explaining wages). 
[B] lacks graduate at the same rate as whites - when one controls for law school grades - and they pass the bar at the same rate as whites with the same grades and background characteristics. So what exactly is there for stereotype threat to explain? (p. 1996)

Sander seeks to boost his case by association, but he does not have a theory of the kind Stigler was referencing. Stigler was talking about a bedrock theory of economics, the theory of utility maximization and its application to the economic theory of regulation. $^{38}$ In arguing that no one had come up with a better theory to explain regulatory action; Stigler recognized that if the theory of utility maximization was not, despite its gaps and shortcomings, supported by a substantial amount of well done research, it would not have influenced economics. ${ }^{39}$ Sander does not have a theory in this sense. What he has is a series of empirical results and an explanation for them. If Sander's empirical analysis has not been well done, the explanation and his "theory" falls with it. We and others have already shown that the research in Systemic Analysis is flawed, and, as the reader is learning, the same is true of Sander's reply.

Sander is similarly wrong in saying that no one else has entered the arena. Tim Clydesdale, in a piece Sander was aware of before he completed Systemic Analysis, suggests, based on his analysis of the BPS dataset, that law school atmosphere may have much to do with the bar passage gap. ${ }^{40}$ Also the now well-supported theory of stereotype threat may also explain part of the gap. The significant negative coefficients on the race variables in Table 2 are consistent with stereotype threat, though they do not prove its existence. $^{41}$

The lion's share of race's impact on law school grades is, however, almost certainly embedded in the systems of inequality that affect these entry index scores themselves. $^{42}$ As Clydesdale's study suggests, ${ }^{43}$ the effects of these inequalities in a

\footnotetext{
${ }^{38}$ George J. Stigler, Nobel Lecture: The Process and Progress of Economics, 91 J. Political Economy 529, 540-42 (1983).

${ }^{39}$ Id. at 543 ("Gradually a consensus emerges among the economists working on the subject: The theory becomes a part of the standard analytical corpus or it dies of neglect.”).

${ }^{40}$ Timothy T. Clydesdale, A Forked River Runs Through Law School: Toward Understanding Race, Gender, Age, and Related Gaps in Law School Performance and Bar Passage, 29 LAW \& SOC. INQUIRY 711 (2004).

${ }^{41}$ Claude M. Steele \& Joshua A. Aronson, Stereotype Threat Does Not Live by Steele and Aronson (1995) Alone, 59 Am. Psychol. 47, 47 (2004) (reviewing how scholars have characterized stereotype threat research and concluding, "[W]hen they do give stereotype threat a special importance, they are not referring to the race gap in the general population but to the race gap in some subsample in which African Americans and Whites have been equated on other factors that might affect their performance....To the extent that the groups have been equated on other causes of the race gap, it may not be overclaiming to emphasize stereotype threat as a principal cause of any remaining gap.”); Geoffrey L. Cohen \& David K. Sherman, Stereotype Threat and the Social Scientific Contexts of the Race Achievement Gap, 60 AM. Psychol. 271, 272 (2005) ("Most important, the focus of stereotype threat is to explain the residual, that portion of variance left over in the racial achievement gap after prior preparation and skills (as roughly assessed by prior indicators such as college board scores) have been controlled.”).

42 Jesse M. Rothstein, College Performance Predictions and the SAT, 121 J. ECONOMETRICs 297, 310-15 (2004) (decomposing SAT scores within seven University of California campuses and finding that students' individual background characteristics (race/gender) and high school characteristics (racial composition of the student body, percentage of students receiving subsidized lunches and parental education levels) account for a substantial share of the variance in SAT scores, and account for much of the
} 
model comparing black to white law school performance can be both direct and indirect since factors associated with being black can both directly lower black law school performance and can lower performance through their earlier effects on index scores. ${ }^{44}$ Sanders 1995 data, as presented in Table 2, confirms Clydesdale's finding of the likely existence of direct racial effects that cannot be reduced to index scores. This effect may be attributable to stereotype threat, campus climate, and/or other yet-to-be-identified factors.

The second feature obscured by Sander's claim is the one we have already emphasized; namely we know relatively little about what causes grade differences between students, including differences between black and white students as groups. Moreover, we cannot exclude race, and even racism, as causes because race is likely to interact with other variables in its effect on grades. Sander's mismatch hypothesis posits just such an interaction effect. But we can now say it has been tested and the best research done so far rejects it. Other interaction effects are similarly possible. Theories

ability of the SAT to predict college grades); Holland, supra note _ , at 220 (noting that higher test scores are associated with many socially desirable educational practices (smaller class size, better computers, etc.). The causal explanation is that these desirable practices are allowing these students to succeed, while the non-causal alternative explanation is that social segregation and SES differences are associated both with higher test scores and better educational practices).

${ }^{43}$ In A Reply to Critics, Sander takes a swipe at Clydesdale's Law \& Social Inquiry article, arguing that the BPS dataset's non-standardized LSAT \& UGPA scores, when used with law school GPAs that are standardized to the law school, produce "results that are nonsensical at best. (p. 1982 n.42) The analysis we included in our Stanford Law Review essay is, however, consistent with Clydesdale's results in that it confirms the direct effects of race on law school GPA (though the direct effects in Sander's NSLSP dataset are smaller than those Clydesdale found the BPS data). In addition, use of law school-standardized or nationally-standardized LSATs and UGPAs produce virtually identical results as the non-standardized data, thus undercutting Sander's criticism of Clydesdale that while valid in theory, is of no consequence in practice. For further discussion of the relative adequacy of Clydesdale's model and controls as compared to Sander's data see our Stanford Law Review critique of Sander (pp. 1877-78 and note 85).

${ }^{44}$ Index scores are explanatory variables in regression models explaining variance in grades and post graduation outcomes, but they are unlikely to be causes of law school performance except perhaps as creators of self confidence. Rather they imperfectly reflect true causal variables such as test taking ability (which might be affected by stereotype threat) and pre-law school levels of those analytic and other skills that are important to law school success. Thus the indirect effect of race on law school performance, although it appears to be mediated by index scores in the regressions that Sander and we use, is in fact mediated by the degree to which race and racial inequality affect the development of the skills one brings to law school. A black student who because of racial segregation had a poorer elementary and high school education than most whites is thus likely to score lower on the index variables and do more poorly in law school than a white or black student who was better educated before entering college. To the extent that the pre-college education of blacks as a group is worse than that of whites as a group and to the extent that this bears on future skill development and learning, one would expect blacks as a group to do worse on the LSAT test and on their UGPAs than whites and one would expect them to do worse on graded law school performance as well. To the extent that living in a world in which blacks are expected to perform less well than white produces stereotype threat that negatively affects test performance, one would similarly expect black students as a group to do worse than white students as a group on LSAT scores, UGPAs, law school grades and bar passage, even if the average skill levels of white and black students is the same. If levels of either pre-college education or vulnerability to stereotype threat are the result of racial prejudices and inequality, then racial prejudices and inequality are the ultimate causes of the differences we see in law school performance. The same may be said of any other variables attributable to inequality that might detrimentally affect the performance of black students relative to whites on the index variables or on tests in or after law school. 
that find importance in role modeling would, for example, suggest that black students' learning would be enhanced relative to that of whites in classes taught by black professors and depressed in classes taught by white professors, ${ }^{45}$ and that is an even greater concern in learning environments where African Americans have only a token presence, ${ }^{46}$ which is precisely what would occur at elite law schools absent affirmative action (see Part III.B.3). Since there are far more white law professors than black ones, the overall effect could substantially depress black student test performance. We have no good test of this theory in the law school context, and many other theories that posit interactions between race and other variables are similarly unexplored. In this world neither we nor Sander can tell the entire grade difference story, and Sander's claim that $90 \%$ of it has to do with index scores and affirmative action cannot be justified.

\title{
3. Law School Grades: Questioning Causation and Curvilinear Effects
}

\section{a. Claims of Causation}

\begin{abstract}
But the overwhelming reason why blacks are clustered at the bottom of their law school classes is the operation of racial preferences. None of the critics seems prepared to deal with this fact. Nor do any of the critics deal with the implications of low grades. Even though the evidence is overwhelming that law school grades are the primary determinant of a student's chances of graduating and passing the bar, all of the critics neglect grades in explaining student outcomes (indeed, Ayres and Brooks construct an elaborate model of outcomes that entirely leaves out law school performance). None of the critics has directly addressed the logic of low grades and the mismatch effect. (p. 1969)
\end{abstract}

When law schools admit students, they do not know the grades those students will receive in law school. So if we want to know the effects of affirmative action on a student's chances of graduating and passing the bar, we must examine the implications of the entering credentials that law applicants present both alone and in interaction with the quality of the school they attend, and not their grades during law school. Sander's use of law school grades might be legitimate if he were seeking to explain which variables known at graduation (or after the first-year) explain bar passage, but when used to evaluate affirmative action, Sander’s claim is a rhetorical sleight of hand.

Sander's argument is as follows: (1) index credentials are important in explaining first year grades (this is true, though at ABA law schools they typically leave about threefourths of the variance in grades unexplained); (2) Grades are important in explaining bar passage (again this is true, though they are far from a complete explanation, as many students with poor grades pass while others with better grades fail); and (3) Therefore, a

\footnotetext{
${ }^{45}$ In our Stanford Law Review essay, for example, we cited the systematic observational study of law school classrooms conducted by Mertz of the American Bar Foundation. See Elizabeth Mertz et al., What Difference Does Difference Make? The Challenge for Legal Education, 48 J. LEGAL EdUC. 1, 74 (1998) ("The most striking [pattern] is the connection between the presence of a teacher of color and greater participation by students of color”).

${ }^{46}$ See e.g., Mischa Thompson \& Denise Sekaquaptewa, When Being Different Is Detrimental: Solo Status and the Performance of Women and Racial Minorities, 2 ANAlyses OF SOCIAL Issues \& PUB. POL'Y 183 (2002).
} 
strong case can be made that we do students a disservice by putting them in schools where their index credentials will mean they receive low grades.

The third point is the sleight of hand, for while the argument appears to have a syllogistic form, the conclusion does not follow from the preceding premises. If the conclusion were true, it should be possible to demonstrate negative effects of affirmative action, based on the information known at the time of admission, namely UGPAs, LSAT scores, other admission-relevant traits, and the quality of the school attended, without any need to consider grades as an intervening mechanism.

Why is it that the unnecessary middleman (i.e., the intervening mechanism: law school grades) must perform so much of the heavy lifting in Sander's argument that affirmative action is to blame for black-white graduation and bar passage disparities? Because, as we noted in the Stanford Law Review, Wightman's research for the LSAC indicates that LSAT scores and undergraduate grades explain only about one-tenth of the variance in eventual bar passage for the law students in the BPS (p. 1883 n.103) and are weak predictors of law school graduation (p. 1873 n.62), an estimate confirmed by Clydesdale. ${ }^{47}$ By assimilating index credentials into law school grades despite the fact that the former typically predict about a quarter of the variance in the latter and then focusing on the relationship of law school grades to graduation and bar passage, which is considerably stronger than the relationship of the index credentials to either of these ultimate outcomes, Sander makes it appear as if admitting a student with index credentials lower than her peers is a prescription for failure. ButSander's logic here does not test the hypothesis he is advancing.

Sander should be examining whether black students with lower index credentials admitted to higher tier schools will do worse than black students with similar credentials admitted to lower tier schools. We did this in our Stanford Law Review essay, and found when one looks at the data in this light, support for the mismatch hypothesis is lacking (p. 1883-6). ${ }^{48}$ Ayres and Brooks, in their response to Sander, reach similar conclusions.

Chambers et al.'s third critique argues that my evidence for the mismatch theory is weak because my regressions predicting graduation and bar passage rates (reported in Tables 5.6 and 6.1 of Systemic Analysis) are weak. Chambers et al. are arguing, in other words, that grades have only a weak bearing on graduation and bar passage, and that therefore I can't be right that black students' disproportionately low grades are substantially hurting their chances of becoming lawyers. I think that Chambers et al.'s arguments would strike most econometricians as misleading and uninformed. (p. 1997).

Sander's claim that we unduly minimize the association between low grades and bar passage is off the mark. We have never disputed that a significant association exists

\footnotetext{
${ }^{47}$ Clydesdale, supra note _, at tbl. 5a.

${ }^{48}$ See also Daniel E. Ho, Reply, Affirmative Action's Affirmative Actions, 114 YALE L.J. 2011, 2013 (2005) (arguing that Sander's newly-minted structural equation model confirms Ho's core criticisms of Systemic Analysis: "(1) that we cannot control for law school grades in estimating the causal effect of tier, (2) that white students are an invalid control group, and (3) that there is no detectable effect of law school tier on bar passage.”).
} 
between law school grades and bar passage. What we have disputed is Sander's claim that low bar passage is caused by low grades and especially that it is caused in a way that ending affirmative action would cure. In his original article he speculates that law students with comparatively low entry credentials receive low grades because, in an environment with students much better qualified academically than they are, they become confused, frustrated, and left behind and never learn what they need to learn. Never having learned the basics, they fail the bar at high rates. Sander, however, never proves this supposition. It is possible, as Sander claims, that black students would learn more where their measured skill level better matched the measured levels of students around them, but it is also possible, as Bowen and Bok's data on elite undergraduate schools suggest, $^{49}$ that there is a learning advantage to working alongside abler students even if one does not achieve as much grade-measured success as most of them.

From his unsupported claimthat law school skill homogeneity affects learning, Sander leaps to an unsupported conclusion: if black students went to schools where their credentials were the same as other students, they would learn more and thus both get higher grades and pass the bar at higher levels. We are not convinced by either his causal explanation or his speculations about what would occur if black students went to lesser schools. Neither he nor we can confidently answer the "what if?" question without an experiment with national law school admissions that could never occur. But, to the extent that the data available to Sander and to us provide evidence (particularly the data in the Bar Passage Study), Sander has not made his case, and the evidence suggests he is wrong. As we have shown above, within the BPS, black students who go to lower tier schools do not ultimately pass the bar at higher rates than black students with the same entering credentials who attend higher tier schools. ${ }^{50}$

It is likely that if black students attended schools where their entry credentials were the same as white students, they would earn higher grades within that school (because they would face less stiff competition), but this does not mean that they would have learned more than they would have in a more competitive school or that they would do better on the bar than similarly credentialed students from more selective schools who were admitted pursuant to affirmative action. Moreover, factors like stereotype threat and lower personal and family wealth would likely mean that the typical black student would be more likely to drop out of law school than a similarly credentialed white classmate and be less likely to pass the bar if she did graduate. Stereotype threat can affect all test taking, including undergraduate exams, the LSAT, law school exams, and the bar exam. ${ }^{51}$ Financial need not only leads to generalized stress, but also makes it more likely that a student will have to earn money while in law school and makes it more difficult to afford a high quality commercial bar preparation course.

\footnotetext{
49 See William G. Bowen \& Derek BoK, The Shape of the River: Long-Term Consequences of CONSIDERING RACE IN COLLEGE AND UNIVERSITY ADMISSIONS 59-65 (1998).

${ }^{50}$ See also Chambers et al., supra note 1, at 1884 tbl.3.

${ }^{51}$ In Systemic Analysis Sander argued against stereotype threat by citing first-year research and writing grades from a subset of NSLSP schools. However, as we noted in our Stanford Law Review essay (p. 1881), this was a small and unrepresentative sample: 46 of the 59 African Americans in this subset attended a single law school, a school that had by far the lowest ranking of the 20 schools in the NSLSP.
} 
The situation is somewhat different with respect to law school graduation since low grades may by themselves, whatever their cause, make some people ineligible to continue and discourage other students, who have not flunked, from continuing. Hence while one can say that low law school grades per se are seldom if ever an important cause of failing the bar, one cannot make the same statement about the relationship between low grades and leaving law school. But there are some important points to keep in mind. First, even where grades are an actual and direct cause of leaving law school, they are mediating the effects of other variables like time spent studying or a school climate that interferes with learning. Second, very few law students in fact flunk out, and BPS students who left law school before graduating frequently given financial rather than grade-related considerations as the principal reason why they left. ${ }^{52}$

\section{b. Curvilinear Effects}

Table 1 organizes the LSAC-BPS data on law student performance in a way that highlights this curvilinear relationship. For the six tiers in the LSACBPS data, it splits all students into twenty demideciles based on law school grades (e.g., the lowest 5\% of the class is in demidecile 1, and the highest 5\% are in demidecile 20)..... The percentages in each column refer to the proportion of students in each grade segment who graduated and passed the bar on their first attempt..... The patterns are very striking. Within each tier of schools, the difference between the first (bottom) demidecile and the second demidecile, in the proportion of students who graduate and take the bar, is very large (an average of 21 points). From the second to the third demidecile, the difference is smaller but still quite large (nearly 8 points). From the third to the fourth demidecile, the difference is still smaller (6.5 points). And so on. In the upper grade reaches, a change in one demidecile improves one's chances of graduating and passing the bar by only 1 or 2 points. (pp.1969-70)

The fact that index scores explain only a small portion of the variance in law students' grades points to a serious flaw in Sander's interpretation of his data. His Reply glosses over the fact that people don't end up at the bottom of their class in law school solely because their LSAT/UGPA index scores are low relative to those of other students. Many students with lower index scores outperform many students with higher ones. Imagine, for example, an entering class of 200 students, where LSAT scores explain 25\% of variance in first-year grades (consistent with LSAC research on academic index scores), and where half the class has LSAT scores of 150 (about the $48^{\text {th }}$ percentile in the national applicant pool) and the other half has scores of 160 (82 ${ }^{\text {nd }}$ percentile). In such a scenario, 16 of the 100 low LSAT students can be expected to end up in the top quarter of the class based upon first-year grades, and 39 will be expected to rank in the top half; conversely 39 of the 100 students with 160 LSATs are likely to end up in the bottom half of the class, with 16 expected to be in the bottom quarter. ${ }^{53}$ Because index scores

\footnotetext{
${ }^{52}$ Wightman, The Threat to Diversity in Legal Education, supra note _, at 37 (“Academic difficulty is not the only reason that some students failed to graduate from law school. Data from the First Follow-up Questionnaire distributed as part of the LSAC Bar Passage Study suggest that financial considerations are among the most common reasons provided by students who dropped out during their first year of law school.”).

${ }^{53}$ Law Sch. Admission Council, New Models to Assure Diversity, Fairness, and Appropriate Test Use in LAW School Admissions 9 (1999); Philip D. Shelton, The LSAT: Good-But Not That Good, Ass'N Of AM. LAW SCHOOLS NewSlETter, Nov. 1997, at 10, 11 (Shelton is executive director of the Law School Admission Council).
} 
correlate less well with bar passage than they do with first year grades, even more mixing can be expected in bar exam pass/fail status among students who take the test.

Sander, in Reply to Critics, acknowledges a number of the failures of Systemic Analysis. One, discussed in the paragraph we quote above, is using a linear model to evaluate relationships that are not linear. He now argues, and offers a table to show, that the relationship between rank in class and first time bar passage is not linear but curvilinear. He may be right, but we would suggest a different possibility; namely, that we do not have a smooth curvilinear relationship, but rather two important thresholds: (1) a lower threshold which separates from everyone else those at the very bottom of the class, who are very unlikely to pass the bar on their first attempt; and (2) a second threshold which varies by tier, above which a student's chances of first-time bar passage is substantial and doesn't increase much after that, if it increases at all. Depending on the tier, there may be one or more step increases between the two principal thresholds reflecting the fact that a student's chance of passing the bar first time through does not increase smoothly in the middle range, but seems to be about the same for a few demideciles and then takes an apparent leap. We suggest that the lower threshold exists because in all schools there are some students who are simply not cut out for the study of law whatever their test scores may be and others who experience major life stresses, including physical and mental illnesses, marital problems, alcoholism and the like, which interferes so substantially with their class attendance and studying that they learn little law and barely manage to pass their courses if they pass at all. There is no reason to believe that these students would do better if they attended less competitive law schools, for their interest in the law or personal problems are unlikely to differ substantially. At the other end, there is a level of legal aptitude and learning above which almost anyone can pass the bar on the first try. These students are bar passers and by definition could not do better passing the bar by attending less competitive law schools. ${ }^{54}$ Our revised version of Sander's Table 1 uses different shades of blue to indicate similar pass rates (e.g., 10-19\%, up to $90-99 \%$ ) at the various law school tiers.

Revised Version of Sander's Table 1 (p. 1970):

Proportion of BPS Cohort (1991) Graduating and Passing the Bar on the First Attempt, by Tier and First-Year Law GPA Demidecile (Showing Variations in Pass Rates with Shades of Blue)

\begin{tabular}{|c|c|c|c|c|c|c|}
\hline $\begin{array}{c}\text { Grade } \\
\text { Demidecile }\end{array}$ & $\begin{array}{c}\text { Tier 6 } \\
\text { (Minority } \\
\text { Schools) }\end{array}$ & Tier 5 & Tier 4 & Tier 3 & Tier 2 & $\begin{array}{c}\text { Tier 1 } \\
\text { (Most } \\
\text { Elite) }\end{array}$ \\
\hline 1 (bottom 5\%) & $10 \%$ & $10 \%$ & $22 \%$ & $27 \%$ & $33 \%$ & $59 \%$ \\
\hline 2 & $21 \%$ & $36 \%$ & $40 \%$ & $51 \%$ & $68 \%$ & $74 \%$ \\
\hline 3 & $19 \%$ & $42 \%$ & $56 \%$ & $67 \%$ & $71 \%$ & $81 \%$ \\
\hline 4 & $26 \%$ & $48 \%$ & $67 \%$ & $77 \%$ & $73 \%$ & $84 \%$ \\
\hline 5 & $31 \%$ & $54 \%$ & $70 \%$ & $84 \%$ & $81 \%$ & $85 \%$ \\
\hline 6 & $35 \%$ & $58 \%$ & $82 \%$ & $83 \%$ & $82 \%$ & $90 \%$ \\
\hline
\end{tabular}

\footnotetext{
${ }^{54}$ Bowen and Bok report a kind of threshold effect among the students in the (mostly elite, 70\% private) College and Beyond database. They find that controlling for other factors, above scores of about 1100, SATs are of little value in forecasting graduation. BOWEN \& BOK, supra note _, at 66 fig. 3.6.
} 


\begin{tabular}{|c|c|c|c|c|c|c|}
\hline 7 & $30 \%$ & $72 \%$ & $79 \%$ & $88 \%$ & $87 \%$ & $96 \%$ \\
\hline 8 & $41 \%$ & $73 \%$ & $86 \%$ & $85 \%$ & $88 \%$ & $95 \%$ \\
\hline 9 & $45 \%$ & $88 \%$ & $84 \%$ & $91 \%$ & $89 \%$ & $96 \%$ \\
\hline 10 & $43 \%$ & $81 \%$ & $90 \%$ & $94 \%$ & $91 \%$ & $99 \%$ \\
\hline 11 & $62 \%$ & $85 \%$ & $89 \%$ & $94 \%$ & $96 \%$ & $98 \%$ \\
\hline 12 & $67 \%$ & $90 \%$ & $93 \%$ & $95 \%$ & $93 \%$ & $98 \%$ \\
\hline 13 & $77 \%$ & $92 \%$ & $93 \%$ & $93 \%$ & $96 \%$ & $97 \%$ \\
\hline 14 & $79 \%$ & $92 \%$ & $93 \%$ & $96 \%$ & $95 \%$ & $98 \%$ \\
\hline 15 & $77 \%$ & $87 \%$ & $95 \%$ & $94 \%$ & $96 \%$ & $100 \%$ \\
\hline 16 & $90 \%$ & $88 \%$ & $96 \%$ & $97 \%$ & $97 \%$ & $98 \%$ \\
\hline 17 & $86 \%$ & $89 \%$ & $96 \%$ & $98 \%$ & $97 \%$ & $96 \%$ \\
\hline 18 & $86 \%$ & $94 \%$ & $97 \%$ & $97 \%$ & $97 \%$ & $98 \%$ \\
\hline 19 & $93 \%$ & $94 \%$ & $96 \%$ & $96 \%$ & $98 \%$ & $98 \%$ \\
\hline 20 (top 5\%) & $97 \%$ & $95 \%$ & $97 \%$ & $98 \%$ & $99 \%$ & $100 \%$ \\
\hline
\end{tabular}

We also read the data in Sander's new Table 1 as substantially refuting his claim that affirmative action hurts black law students by concentrating them toward the bottom of their classes. For example, students in the bottom 5\% of the class in Tier 1 schools have a better chance of passing the bar on the first attempt than those in the middle of their class in Tier 6 (historically minority) schools, or those at the $15^{\text {th }}$ percentile in Tier 4 law schools. Students at the $30^{\text {th }}$ percentile in Tier 1 have a better chance of being firsttime bar passers than students at the $45^{\text {th }}$ percentile in Tier 2 . Students at the $20^{\text {th }}$ percentile in Tier 3 have a better chance of passing on the first attempt than students at the $40^{\text {th }}$ percentile in Tier 5 and the same chance as students at the $65^{\text {th }}$ percentile in Tier 6. Students at the $45^{\text {th }}$ percentile in Tier 3 have a better chance of being first time bar passers than students at the $85^{\text {th }}$ percentile in Tier 5 , and the same can be said of students at the $50^{\text {th }}$ percentile in Tier 4 law schools. And so on.

Consistent with the idea of threshold and step effects, not all differences are so stark. For example, if one is in the top half of her class, the likelihood that she will pass the bar on her first attempt seems unaffected by whether she is at a tier one, tier two or tier three school. Still the tendency of those of a given class rank to do better if they are in higher tier schools seems very strong and unlikely to be an artifact of chance. If one looks across the rows rather than down the columns, there are 300 comparisons that can be made. In only 16 cases is the average pass rate for students of a given rank higher for students in schools in a lower tier. There are 12 ties, and in the 272 remaining cases, students whose grades place them in the same demidecile do better if they are in a higher rather than a lower tier, though differences, particularly between schools that have reached the top step of success, are not going to be statistically significant. The lesson seems to be that wherever a student is ranked in her law school class, for purposes of first-time bar passage she is better off than if she finished in the same place in a lower tier school. Moreover students in a given rank are often better off than they would have been with a higher class ranking at a lower tier school.

Sander's Table 1 does not, however, address the issues that most concern us, for it reports the success rate for all students when our concern is with black students, particularly black students who benefited from affirmative action. Moreover, it is confined to first-time bar passage. When it comes to producing lawyers it is eventual bar 
passage that counts. Had Sander used the latter as the dependent variable, success rates at all levels would have risen.

There is nothing surprising about the pattern we observe. We would expect students near the bottom of their class in more selective law schools, or at any given rank for that matter, to have been more able at admission than students who ranked similarly at less selective schools. Yet, whether students in the $5^{\text {th }}$ to $10^{\text {th }}$ percentile of tier 1 and 2 schools were similarly more able at admission than students at the $60^{\text {th }}$ percentile of tier 6 schools, who had similar first-time bar pass rates, is a different question that the data do not allow us to answer, either generally or in the case of black students in particular. Thus, it seems certain that the pattern we see is in large measure due to selection effects. Some of the bases for selection, like index scores, we (and Sander) can measure and include in our models. Others are unmeasured and pose the threat of selection bias.

\title{
4. Selection Bias and Black-on-Black Comparisons
}

\begin{abstract}
In the fall of 2002, when I first looked at the LSAC-BPS database with a view to studying racial preferences, I thought the most straightforward way to examine the effects of affirmative action was to compare the outcomes of blacks with similar credentials who were attending schools in different tiers. Using simple regression techniques, I found that, depending on exactly how the equation was specified, the effects of going to a more elite school seemed to be either mildly negative or neutral. I tentatively concluded that preferences were probably a minor part of the story...

When I returned to these questions in the spring of 2003, I realized that I had made two fundamental errors in my analyses. First, I had overlooked the problem of "unobserved characteristics." (pp. 1971)
\end{abstract}

In our response to Systemic Analysis we presented data showing that contrary to the findings Sander cites above, black students with similar index scores do, on average, at least as well when it comes to graduating and passing bar if they attended higher rather than lower tier schools and noticeably better if they attended top tier schools. Sander's response to these data is twofold. The first is to retreat from Systemic Analysis, in which he writes as if holding index scores constant, black students in the BPS data set did better on the bar if they attended lower rather than higher ranked law schools. ${ }^{55}$ Sander no longer suggests this. Rather, he makes the more subtle claim that holding ability constant, a black student will do better on the bar if he attends a lower rather than a higher tier school, assuming that his ability does not match that of white students in the higher tier school. Sander then argues that where students with the same index scores are

\footnotetext{
${ }^{55}$ This suggestion is a logical corollary of Sander's comparison of black and white law students with equivalent academic index scores. See Sander, Systemic Analysis, supra note 2, at 441 ("At a given index level, blacks have a much higher chance of failing the bar than do whites-apparently, entirely as a result of attending higher-ranked schools and performing poorly at those schools. Indeed, the consequences of affirmative action — in terms of passing the bar — seem to be roughly equivalent to subtracting 120 points from the academic index score of the typical black student..."); see also id. at 479 ("Blacks are nearly six times as likely as whites to not pass state bar exams after multiple attempts. The difference, again, is mostly attributable to preferences. Half of the black-white bar passage gap is traceable to the effects of blacks with good credentials getting low grades at higher-prestige schools; nearly a quarter is due to lowprestige schools admitting blacks with lower credentials than almost any of the other students in the system.”).
} 
in more and less selective law schools, the students in the more selective (higher tier) school are in fact more able because of selection bias. In other words, when selective law schools admit students with relatively low index scores, they do so because aspects of the student's application which are unobserved in the BPS data set, letters of recommendation say, suggest that the student is better equipped for the study of law than his index score makes her appear.

We agree with Sander that he erred by ignoring unobserved characteristics is his models of law school and bar performance, though the problem is not simply that characteristics are unobserved. Rather, when unobserved characteristics might affect a dependent variable and when they are not likely to be randomly distributed across sample cases, one has the problem commonly called selection bias. We discuss this issue in our Stanford Law Review essay (pp. 1885-86). ${ }^{56}$ If Sander was aware of this problem a year before Systemic Analysis went to print, he nonetheless did not use modeling techniques that control for selection bias. He highlights the problem in A Reply to Critics but in Systemic Analysis he barely mentions it, only dropping a footnote to say he didn't

\footnotetext{
${ }^{56}$ One might ask why, if Sander's model was defective for failure to model selection bias, we did not attempt to model it in our critique of Sander? The reason for the difference is that Sander was attempting a causal analysis to support his claim that black students were in fact hurt by going to schools that only affirmative action allowed them to attend. We, on the other hand, were looking at how black students in the various tiers did to see if Sander's claim that they were in fact hurt by affirmative action was true. The world we were examining was one in which results were and should be affected by selection bias. Indeed, that is arguably what affirmative action admissions aims for. Admissions officers seek to admit those students who despite low index scores will graduate from law school, have little trouble with their academics, pass the bar and have successful legal careers. If those schools that have the have the most scope for selection, usually schools that have the highest prestige and the highest quality applicant pools, do their job well, then their students should do better on the bar and in their careers than students attending less selective schools, though they may not do better on rank in class because class ranks in all schools span the same range, and they may not do better on their first year grades if the grading curves of schools in different tiers are similar. Thus the fact that, controlling for index scores, black students who go to elite schools are, in most index score ranges, more likely to graduate and pass the bar than black students with similar credentials who enter less elite schools is not only evidence for selection bias but also suggests the affirmative action admissions systems in these schools are working, at least to the extent that, according to our analysis and the independent analyses of Ayres and Brooks and Ho, black students are not disadvantaged when it comes to becoming lawyers by any mismatch effect.

Our goal, in other words, was to evaluate Sander's claim that the black students in the BPS data in fact did worse after controlling for index scores and a few other variables if they attended higher rather than lower tier schools. We found, as we demonstrated in our reply, that Sander's claims were not supported by the data. Sander never acknowledges that we have shown his original analysis to be wrong, but he seems not to dispute this, for his claim in A Reply to Critics rests on new ground. Now his claim is that even if our analyses (and his) failed to show that black students in lower tier schools outperformed apparently similar black students in higher tier schools, this would have been the result had these analyses controlled for relevant unmeasured variables. This is an argument Sander would not have to make if his original results were sound.

If Sander were able to demonstrate in his A Reply to Critics that selection bias implies that the black students in higher tier schools would have done even better in the hypothetical world where they attended a lower tier school, then to refute his claim we too would have to consider selection bias and control for unmeasured variables. We shall see that despite his claims Sander does not control effectively for selection bias, and to the extent he controls it at all, Ayres and Brooks' superior model refutes his suggestion that selection bias means that black students attending higher tier schools would have done even better had they too begun at lower tier schools because they were in fact more able than the students to whom they are being compared.
} 
concern himself with selection bias because it would cut against the hypothesis he was advancing. ${ }^{57}$ His concern for selection bias grew only after his critics made it clear that his original analyses of the BPS data did not support his mismatch hypothesis. In these data, the mismatch theory is consistently refuted by the performance of black students at elite schools and was not systematically supported by the performance of black students in Tiers $2-6$ institutions.

Important implications flow from Sander's attention to selection bias in A Reply to Critics. First, his new awareness corroborates his critics' claim that he cannot defend the methodology in Systemic Analysis. The careful reader will note in his Reply his failure to even comment on, much less refute, specific claims regarding the weaknesses and errors of the statistics used in Systemic Analysis. Rather Sander attempts to defend Systemic Analysis by arguing that new and improved methods lead to the same conclusion.

A centerpiece of Sander's effort to take account of selection bias in making blackon-black comparisons across BPS tiers is his "national grade" method of adjusting UGPAs, which is premised on the twin propositions that holding LSAT scores constant an admissions officer is more likely to admit a student with a 3.5 average from a school like Yale than she is a student with a 3.5 from neighboring University of Bridgeport, and that the student with the 3.5 from Yale is generally more able than the student with the 3.5 from Bridgeport with the same LSAT score. To state this more generally, Sander's new measure is based on the assumptions that the higher the average score of LSAT takers from a given school, the more likely law school admissions officers are to admit students from that school with a given grade-point average, and, more importantly, the more able the student is relative to graduates of other schools with the same LSAT score and grade-point average. ${ }^{58}$

One can use the LSAC data to compare someone who gets a 3.5 from College $X$ with someone who gets a 3.7 from College Y. I call this adjusted UGPA a student's "national grade." Using this translation significantly improves the ability of UGPA to predict law school performance (p.127 n.67).

We do not find Sander's claim that he has developed a superior measure of UGPA persuasive. Assuming that we understand how Sander constructed his measure of national grades, ${ }^{59}$ we have serious problems with his building of and justification for this measure and with his use of these constructed grades in his analyses. First, Sander once again makes the mistake of reporting statistical significance without providing information about practical significance, such as changes in $\mathrm{R}^{2}$ values (we asked Sander

\footnotetext{
${ }^{57}$ Sander, Systemic Analysis, supra note 2, at 449 n.220. The claim is true in the sense that when it comes to his bottom line, selection bias should cut against the hypothesis he is advancing, but Sander ignores the fact that selection bias can affect the causal implications of other variables in and the overall adequacy of a model.

${ }^{58}$ See Richard H. Sander, Mismeasuring the Mismatch: A Response to Ho, 114 Yale L.J. 2005, 2010 (2005) ("There are systematic, biasing reasons why one student is at the University of North Carolina and another with similar numbers at Duke.”).

${ }^{59}$ In Reply to Critics Sander does not describe in detail the steps he took to construct his national grade measure, nor did he do this in his web site after Reply was published or in response to our e-mails.
} 
for this information in June of 2005, repeating the request last November, and have not heard back from him). ${ }^{60}$ Second, the relevant question is not whether Sander's "national grade" method significantly improves the ability of UGPA to predict law school grades (much less -- since Sander makes such a strong causal argument -- bar passage). Rather, the question is how much the national grade adjustments enhance the prediction of law school grades from the LSAT/UGPA index scores. Any UGPA adjustment method, including Sander's, that is anchored to LSAT data for each college, will necessarily "launder" some information about students' LSAT scores through their UGPAs, and just as a UGPA-LSAT index does a better job than UGPA alone in predicting law school grades, so will a "national grade" which incorporates into the UGPA some information about LSAT score. ${ }^{61}$ Thus, it would not be surprising if the predictive power of Sander's "national grade" UGPA is higher than unadjusted UGPA for reasons unrelated to whether the new measure more accurately gauges the relative abilities of students with nominally similar grades at different schools. ${ }^{62}$ Third, we note that the LSAC after repeatedly studying the issue using larger datasets than Sander's, recommended against UGPA adjustments for a combination of psychometric and equity reasons, and accordingly, in reporting applicant data LSAC has not made UGPA adjustments on behalf of law schools since the 1970 s. $^{63}$

Though it is a side issue in the current discussion, it is nonetheless important to note that the prominent role Sander now gives to selection bias effectively refutes Section III of Systemic Analysis (pp. 390-410), in which he claims that law schools, including the University of Michigan, are being deceitful when they claim to be giving considerable

\footnotetext{
${ }^{60}$ This was a point of criticism in our Stanford Law Review essay (p.1869). See also Am. PsYCHOL. Ass'N, Publication MANUAL 25-26 (5 $5^{\text {th }}$ edition, 2001) (" [I]t is almost always necessary to include some index of effect size or strength of relationship in your Results section...The general principle to be followed...is to provide the reader not only with information about statistical significance but also with enough information to assess the magnitude of the observed effect or relationship.”).

${ }^{61}$ To illustrate this point, consider an extreme case where every law school applicant from undergraduate colleges A and B have 3.5 UGPAs, but all college A applicants have LSAT scores of 165 while all college B applicants have LSATs of 155. If we inflate the UGPAs of college A's students and deflate the UGPAs of college B's students to reflect the colleges' different LSAT score averages, we will clearly do better in predicting the law school grades of students from these two schools so long as the LSAT score has some predictive validity. UGPAs alone would obviously not predict anything because they are identical. The national grades would predict better than the actual UGPAs not because grading at college A was more rigorous than grading at college $\mathrm{B}$, but because the difference in national grades would capture differences in LSAT scores.

${ }^{62}$ See Donald A. Rock \& Franklin R. Evans, The Effectiveness of Several Grade Adjustment Methods for Predicting Law School Performance, in LAW SCH. AdMISSION COUNCIL, REPORTS OF LSAC SPONSORED RESEARCH: VOLUME IV, 1978-1983 363, 372-75 (1984) ("When the adjusted UGPA instead of unadjusted UGPA is used in conjunction with LSAT to obtain PFYA [predicted first-year average], the relative contribution of LSAT to PFYA is slightly reduced. The increase due to grade adjustment in the correlation between UGPA and FYA is probably larger than the increase in the multiple correlation because LSAT itself acts as an 'adjuster' of undergraduate grades, consequently, 'stealing some of the thunder' of the adjusted grades."); David Kaye, $A n$ " $A$ " is an " $A$ " is an " $A$ ": An Exploratory Analysis of a New Method for Adjusting Undergraduate Grades for Law School Admissions Purposes, 31 J. LEGAL. EdUC. 233, 23738 (1981) (UGPA adjustments at Arizona State improved the correlation of UGPA with FYA by about .08.09, but only improved the correlation between index scores and FYA by .04, which was equivocal in terms of statistical significance).

${ }^{63}$ Cheryl I. Harris, Critical Race Studies: An Introduction, 49 UCLA L. REV. 1215, 1224 n.19 (2002).
} 
weight to characteristics other than the index variables and that law schools engage in individualized review in "relatively few cases" at the margin. ${ }^{64}$ If these earlier claims were correct, then the kinds of unmeasured variables that concern Sander now could not bias the data because they would not be factors in the admissions process. ${ }^{65}$ It is only because we think Sander's characterization of how the admissions process works at Michigan and other law schools is mistaken that we take his current concern with selection bias as seriously as we do. We are happy that he too is now rejecting his characterization of how law schools admit students, but the closest he comes to admitting it is in statements like the following:

Thus, there was very likely something different between a black law student with an index of 600 attending a "Tier 1 " school, and a black student with the same index attending a "Tier 3" school-some quality that led the Tier 1 admissions committee to admit the first student but not the second. I could only control for their LSAT and UGPA and, important as these characteristics were, it was pretty much certain that the Tier 1 student had some other characteristic not in the LSAC-BPS data set-such as attendance at a stronger college, a degree in a more challenging major, or a pattern of strong academic improvement during college-that made him more likely to succeed than the facially similar Tier 3 student. (pp. 1971-72)

Failing to renounce his claim about Justice O'Connor's majority opinion in Grutter and then criticizing Ayres and Brooks (and the four of us) at length about selection bias amounts to having it both ways. Either law schools do not give considerable weight to characteristics other than index scores in admissions (in which case selection bias is not the vexing problem Sander makes it out to be), or law schools are giving meaningful weight to these variables, in which case the reader should skip past twenty pages of Sander's article because he now has refuted Section III. One wonders

\footnotetext{
${ }^{64}$ See e.g., Sander, Systemic Analysis, supra note 2, at 409 ("I have thus far been unable to find a single law school in the United States whose admissions process operates in the way Justice O'Connor describes in Grutter. The academic index for applicants - however it might be constructed by individual schools - is always the dominant factor in admissions within each racial group; other 'soft' factors play a prominent role only for those relatively few cases that are on the academic score boundary between 'admit' and 'reject."”).

${ }^{65}$ While Sander writes about "some quality that led the Tier 1 admissions committee to admit the first student but not the second," (p. 1971) which suggests that selection bias is a function of admission decisions, there is, however, another source of selection bias, unrecognized by Sander, which could still be at work. This is selection on the part of applicants, for applicants select schools to apply to just as schools select which applicants to admit. If, among students with similar credentials, more able students apply to more selective schools either because they are more confident of their ability to make the grade than less able students or because they are encouraged to apply to these schools by friends and advisors who appreciate their special talent, then one has another reason to expect students at more selective schools to be stronger than students at less selective schools on unmeasured variables. If, however, Sander is correct in arguing that "large majorities of law school applicants go to the most elite school that accepts them," Sander, Mismeasuring the Mismatch: A Response to Ho, supra note _, at 2010, then selection bias effects are likely to be small because most students apply to one or more "reach" schools (as we noted in the Stanford Law Review at p. 1865 n. 33, in 2003 only 4 of 183 law schools admitted more than half of their applicants) and students are most likely to judge their chances of acceptance by their index scores since these are the most concrete and visible bases on which schools make admissions decisions. Moreover, if a black student's score is below the range from which a school regularly admits students, the student's special characteristics must become visible to the admission's officer before he is advantaged by them. In this case if one could model the factors that shape school selection, one would account for the characteristic that led the applicant to self select.
} 
why Sander would write as he did in Systemic Analysis, if in 2003 he realized that much else was going on. ${ }^{66}$

\title{
5. The Tiers in the Bar Passage Dataset
}

\begin{abstract}
My second oversight was not recognizing at first the weakness of the LSAC-BPS "tier" variable for measuring eliteness. Linda Wightman, the LSAC official who created the tier variable, used a total of seven factors to create "clusters" of schools with similar characteristics. The factors included school size, cost, selectivity, faculty/student ratio, minority percentage, median LSAT score, and median UGPA. Several of these correlate strongly with prestige, of course, and the clustered tiers as a whole are a perfectly reasonable proxy for prestige, when one takes their limitations into account. But as a method of selecting pairs of students to compare, assuming the clusters perfectly measure relative prestige is a methodological disaster. The two largest clusters of schools-Tiers 3 and 4 in my table-have between them nearly two-thirds of all law schools and law students, but heavily overlap in the credentials of their students. In other words, the more competitive of the Tier 4 schools are almost certainly more highly ranked than the least competitive of the Tier 3 schools. To belabor the point, many "Tier 4 students" actually attend more elite schools than some "Tier 3 students," even though Tier 3 as a whole is more elite. (pp. 1972-73)
\end{abstract}

Sander makes a valid point, but he most likely overstates the extent of the problem. Tables 3.1 and 3.2 in Systemic Analysis (pp. 415-16) presents median index scores for blacks and whites by BPS Tier. Looking at median scores for whites, a substantial distance separates all schools except Tiers 2 and 3 and Tiers 5 and 6. Looking at median black student index scores only tiers 3 and 4 as well as 5 and 6 seem close to each other. Reading Wightman's descriptors it appears overlap is most likely between Tiers 3 and 4 and between Tiers 5 and 6, though as we have pointed out, Tier 6 consists of historically minority schools which, apart from index scores, clearly differ on a number of dimensions from Tier 5 schools. Finally, looking at Table 1 in A Reply to Critics (p. 1970), we see that controlling for rank in class, there is a consistent tier effect such that for a given class rank students in the higher tier almost always do as well or better on their first bar exam than students in all lower tiers. The greatest blurring seems to be between tiers 2 and 3 as that is where the most reversals are found. Thus, while the overlap Sander points to introduces noise into the data, it is likely that Tier is still a reasonably valid indicator of prestige and other differences between law schools. ${ }^{67}$ Importantly, in terms of both index scores and bar performance, Tier 1 schools seem to be distinctly superior to schools in all other tiers, so conclusions about the effects of affirmative action on students in elite schools are likely to be the most reliable. Black students in these Tier 1 schools graduate and pass the bar at high rates, and we know from other studies that most go on to have quite successful careers. ${ }^{68}$ Moreover,

\footnotetext{
67 The problem Sander points to does, however, make it important to include law school tier as a series of dummy variables rather than as a continuous variable in regression models. This is how we treated law school tier in our response to Sander. Sander treated law school tier as if it were a continuous interval variable in most of his analyses, and we criticized him for it. We are glad to see that he now acknowledges the force of our criticism even if he does not credit us with it.

68 Richard O. Lempert et al., Michigan's Minority Graduates in Practice: The River Runs Through Law School, 25 LAW \& SOC. INQUIRY 395 (2000); DAVID WILKINS ET AL., HARVARD LAW SCHOOL: REPORT ON THE STATE OF BLACK AlumNi, 1969-2000 (2002).
} 
controlling for index scores black students at Tier I schools do better in graduating and bar passage than black students who attend lower ranking schools.

\title{
6. The Second-Choice Data
}

\begin{abstract}
Although they seem to have misinterpreted the implications of their own discovery, Ayres and Brooks uncovered the most important new data brought to light since the publication of Systemic Analysis. As they explain in their piece, the LSAC-BPS study asked entering law students in 1991 about their process of applying to and selecting law schools. Something like one-tenth of all students in the study reported that although they were admitted to their top-choice school, they passed up that school for geographic or financial reasons and attended a lower-choice school instead. I refer to these students as the "second-choice" sample. This represents an almost ideal way to test the mismatch theory within a pool of black students. The blacks who voluntarily chose to go to a lower choice school should be students who were capitalizing on a smaller racial preference and should have credentials that put them closer to most of their classmates. We do not face the general problem of unobserved characteristics, because these students were by definition strong enough to get into a more elite school. The data is not as ideal as the Dale-Krueger casessince we cannot actually match pairs of students according to which school accepted them, nor can we measure exactly how much "prestige" the second-choice students passed up-but it is close. (p.1973)
\end{abstract}

As Sander acknowledges, Ayres and Brooks cleverly identified within the BPS dataset a group of students who were admitted to two or more school but who chose to attend their second-choice school (presumably lower ranked). Like Ayres and Brooks, Sander has used comparisons of the performance of the "second-choice" black students with other black students to draw inferences how black students of any given index score would likely perform if they went to a school where their entry credentials were closer to those of white students. We too were impressed by Ayres and Brooks' approach, replicated some of their analyses after reading a draft of their article, and in our response agreed with their conclusions.

While Ayres and Brooks "second-choice" analysis reaches more defensible conclusions than Sander's analysis, we now believe that the despite the claims made for it, second-choice analysis is infected to a substantial degree by the problem of selection bias that both Ayres and Brooks as well as Sander were seeking to avoid. If one looks at Table 4 in Sander's reply (p. 1977), one sees that those blacks who passed up their firstchoice school are similar to other blacks on all variables but two, their concern for the cost of legal education and the financial aid package they received. Seventy-five percent of blacks who passed up their first-choice schools gave the financial aid package as a reason for choosing their school, compared to $46 \%$ of other blacks. Our Table 3 breaks these data down further by tiers.

In all tiers but the lowest-ranked predominantly white law schools, black students attending their second-choice law schools were considerably more likely than first-choice students to say that the availability of financial aid was a very important factor in their choice of which law school to attend, and in all tiers they are considerably less likely to say that financial aid did not matter at all. Indeed, only 12 of the 170 second-choice law students said that the availability of financial aid was not at all important in their choice of law schools. Moreover, 107 first-choice black students said that the financial aid 
package was a drawback to the law school they chose, while only 4 second-choice black students said this. $^{69}$ It would thus appear that many black students who passed up their first-choice schools may have been, in effect, "bought" by the school they attended or at least were more price-sensitive than the average black student. To the extent that schools give generous financial aid packages to black students whom they think are especially talented, students attending their second-choice schools will have been selected, perhaps largely, on the basis of unmeasured factors that distinguish them from their nearest apparent peers, factors that are likely to predict to law school success.

Table 3:

Importance of Financial Aid to African American Students by Law School Tier

\begin{tabular}{|lcccc|}
\hline Tier & \multicolumn{2}{c|}{$\begin{array}{c}\text { Very Important } \\
\text { (\# of cases) }\end{array}$} & \multicolumn{2}{c|}{$\begin{array}{c}\text { Not Important } \\
\text { (\# of cases) }\end{array}$} \\
\hline & $\mathbf{1}^{\text {st }}$ Choice & $\mathbf{2}^{\text {nd }}$ Choice & $\mathbf{1}^{\text {st }}$ Choice & $\mathbf{2}^{\text {nd }}$ Choice \\
\hline Elite & 45.7 & 81.3 & 20.9 & 6.3 \\
& $(59)$ & $(13)$ & $(17)$ & $(1)$ \\
\hline Prestige & 47.4 & 81.0 & 23.9 & 4.8 \\
& $(117)$ & $(17)$ & $(59)$ & $(1)$ \\
\hline $2^{\text {nd }}$ Tier & 49.2 & 76.4 & 28.4 & 9.1 \\
Public & $(227)$ & $(42)$ & $(131)$ & $(5)$ \\
\hline $2^{\text {nd }}$ Tier & 47.0 & 82.1 & 25.3 & 5.1 \\
Private & $(182)$ & $(32)$ & $(98)$ & $(2)$ \\
\hline $3^{\text {rd }}$ Tier & 59.8 & 62.5 & 22.7 & 0 \\
& $(58)$ & $(5)$ & $(22)$ & \\
\hline Historically & 33.0 & 55.2 & 35.7 & 10.3 \\
Black & $(98)$ & $(16)$ & $(106)$ & $(3)$ \\
\hline
\end{tabular}

Sander acknowledges, and we see from Table 4, that his second-choice black sample appears stronger than his first-choice students on the index variable. $60.3 \%$ of first-choice black students have index scores in the lowest decile (bottom tenth) for all students compared to $36.5 \%$ of black second-choice students, and only $14.1 \%$ of black first-choice students have index scores at the $4^{\text {th }}$ decile or higher (ranked in the top threefifths) for all students on up compared to 28.8\% of second-choice students. Sander's second-choice students are thus so much stronger than the first-choice students on what we can measure that it is likely they are also significantly stronger on what we cannot measure. Because students respond to financial aid packages in choosing law schools, it appears likely that Sander's second-choice analysis is at least as seriously affected by selection bias as his original analysis. It is thus not surprising that the second-choice black students do significantly better than other students the first time they take the bar.

\footnotetext{
${ }^{69}$ Some first-choice students were only accepted by one law school so without a choice between schools one would not expect them to weigh financial aid as heavily in deciding what law school to attend, but even these students had a choice of what schools to apply to in the first instance and had to decide whether attending law school was worth it. The data suggest that many of them were influenced by financial aid packages in making these decisions.
} 
Table 4:

Percent of Black Students in $1^{\text {st }}$ and $2^{\text {nd }}$ Choice Samples Within Index Deciles

\begin{tabular}{|c|c|c|c|c|}
\hline $\begin{array}{l}\text { Academic Index Deciles } \\
\text { (For All Students) }\end{array}$ & & $1^{\text {st }}$ Choice & $2^{\text {nd }}$ Choice & Total \\
\hline 1st Decile (lowest 10\%) & $\begin{array}{l}\text { Number } \\
\text { \% within }\end{array}$ & $\begin{array}{r}1006 \\
60.3 \%\end{array}$ & $\begin{array}{l}\mathbf{6 2} \\
36.5 \%\end{array}$ & $\begin{array}{r}1068 \\
58.1 \%\end{array}$ \\
\hline $2^{\text {nd }}$ Decile & $\begin{array}{l}\text { Number } \\
\quad \% \text { within }\end{array}$ & $\begin{array}{l}283 \\
17.0 \%\end{array}$ & $\begin{array}{l}39 \\
22.9 \%\end{array}$ & $\begin{array}{l}322 \\
17.5 \%\end{array}$ \\
\hline $3^{\text {rd }}$ Decile & $\begin{array}{l}\text { Number } \\
\text { \% within }\end{array}$ & $\begin{array}{l}144 \\
8.6 \%\end{array}$ & $\begin{array}{l}\mathbf{2 0} \\
11.8 \%\end{array}$ & $\begin{array}{r}164 \\
8.9 \%\end{array}$ \\
\hline $4^{\text {th }}$ Decile & $\begin{array}{l}\text { Number } \\
\text { \% within }\end{array}$ & $\begin{array}{l}73 \\
4.4 \%\end{array}$ & $\begin{array}{l}22 \\
12.9 \%\end{array}$ & $\begin{array}{l}95 \\
5.2 \%\end{array}$ \\
\hline $5^{\text {th }}$ Decile & $\begin{array}{l}\text { Number } \\
\text { \% within }\end{array}$ & $\begin{array}{l}53 \\
3.2 \%\end{array}$ & $\begin{array}{l}10 \\
5.9 \%\end{array}$ & $\begin{array}{l}63 \\
3.4 \%\end{array}$ \\
\hline $6^{\text {th }}$ Decile & $\begin{array}{l}\text { Number } \\
\text { \% within }\end{array}$ & $\begin{array}{l}41 \\
2.5 \%\end{array}$ & $\begin{array}{l}9_{5.3 \%} \\
\end{array}$ & $\begin{array}{l}50 \\
2.7 \%\end{array}$ \\
\hline $7^{\text {th }}$ Decile & $\begin{array}{l}\text { Number } \\
\text { \% within }\end{array}$ & $\begin{array}{l}27 \\
1.6 \%\end{array}$ & $\begin{array}{l}3 \\
1.8 \%\end{array}$ & $\begin{array}{l}30 \\
1.6 \%\end{array}$ \\
\hline $8^{\text {th }}$ Decile & $\begin{array}{l}\text { Number } \\
\text { \% within }\end{array}$ & 24 & 1 & $\begin{array}{l}25 \\
1.4 \%\end{array}$ \\
\hline $9^{\text {th }}$ Decile & $\begin{array}{l}\text { Number } \\
\quad \% \text { within }\end{array}$ & $12.7 \%$ & $\begin{array}{l}3 \\
1.8 \%\end{array}$ & $\begin{array}{l}15.8 \% \\
.8 \%\end{array}$ \\
\hline $10^{\text {th }}$ Decile (highest $10 \%$ ) & $\begin{array}{l}\text { Number } \\
\text { \% within }\end{array}$ & $\begin{array}{ll}6 & \\
& .4 \%\end{array}$ & $\begin{array}{l}1 \text {.6\% } \\
\end{array}$ & $\begin{array}{ll}7 & \\
\quad .4 \%\end{array}$ \\
\hline Total & $\begin{array}{l}\text { Number } \\
\text { \% within }\end{array}$ & $\begin{array}{l}1669 \\
100.0 \%\end{array}$ & $\begin{array}{l}170 \\
100.0 \%\end{array}$ & $\begin{array}{l}1839 \\
100.0 \%\end{array}$ \\
\hline
\end{tabular}

While the black second-choice students have significantly stronger index scores than first-choice black students (Table 4), what is surprising is that second-choice black students do not do better on their overall bar pass rates. Indeed, selection bias makes it plausible to turn Sander's claims on their head, for there is at least some reason to believe that if we could measure all factors that predict to success on the bar, those students who have gone to less selective schools than they might have attended at the end of the day fare somewhat worse on the bar because they chose to attend less competitive law schools. We do not, however, advance this as a strong claim, for too little is known about the difference between first and second-choice students. This second-choice group could easily be large enough to explain the difference between first time bar pass results in Sander's "second-choice" and "other" groups. 
The presence of selection bias is simply one reason why Sander's second-choice analysis cannot rescue the mismatch claims he makes in Systemic Analysis from the criticisms they received. Sander's analysis of the second-choice students also fails to support his case against affirmative action in other respects. There are, for example, problems with his assumption that a student's second-choice school will always be less prestigious and hence less selective than the students first-choice. In some cases the prestige and selectivity of first and second-choice schools may overlap or even be reversed. ${ }^{70}$ Sander's perspective that ordinarily students prefer to go to the most prestigious school they can (and that prestige correlates highly with selectivity) is almost certainly correct, but without further evidence, we don't think one can assume that exceptions are rare. Law students' choices about where to enroll are affected by location, romantic and family relationships, lower in-state tuition, perceived strength in specialties and many other variables that have little or nothing to do with school selectivity or the quality of the overall student body. ${ }^{71}$ For example, among students applying to both UCLA and Northwestern (schools with similar rankings), UCLA might be the firstchoice of many price-sensitive California residents or students who are interested in Critical Race Studies or public interest law concentrations, whereas Northwestern might be the first-choice of many interested in making connections in the Midwest or those attracted by the reputation of particular J.D./Ph.D. programs (sociology, economics, etc.). Likewise, one student may prefer Georgetown over Cornell because the former has a large class size and plum internship opportunities in the Capitol, while another student may prefer Cornell because of its small class size and idyllic setting in Ithaca.

More importantly, we would expect there to be little difference between the quality of the first and second-choice schools for most of the second-choice sample. Even students willing to give up some prestige for financial aid or other benefits are unlikely to want to trade off much in the way of prestige. It is one thing to go to the school that U.S. News ranks $15^{\text {th }}$ rather than $5^{\text {th }}$; it is quite another thing to give up the $5^{\text {th }}$ ranking school to attend the $50^{\text {th }}$ ranking school. Similarly, we expect that most students admitted to more than one law school have generally applied to schools of about the same selectivity or quality (except for one or two safety schools). This makes sense given that black applicants applied to an average of only 4.2 law schools. ${ }^{72}$ If a black student chooses to attend UCLA rather than NYU to be able to live at home (or pursue opportunities in entertainment law), there will be virtually no diminution in the degree of mismatch as Sander conceives it, even though NYU ranks about 7 places above UCLA in most surveys. For example, Sander's approach would lead one to believe that numbers of second-choice students who could have gotten into elite schools went to Prestige schools

\footnotetext{
${ }^{70}$ Some students may think they are attending a less selective school rather than a more selective one but be mistaken as they are biased by local name recognition. Indeed, in some cases a student may have opted for a second-choice school because it was the more selective school and had a better reputation. When one of us was at Harvard he knew students who said that Harvard really wasn't their first-choice but that once admitted they felt they had to go there or they were pressured by their parents to go there. We don't claim this is common but the second-choice sample may include some students who were more "mismatched" than they would have been at their first-choice institutions.

${ }^{71}$ See responses to BPS Entering Student Questionnaire, questions about factors that were important to respondent in choosing law school to attend.

${ }^{72}$ Chambers et al., supra note 1, at 1864.
} 
or $2^{\text {nd }}$ Tier schools instead. Perhaps they did, but the data don't suggest this, for a higher proportion of second-choice black students (9.4\%) than first-choice black students (7.8\%) attended elite schools. Whatever the first-choice of these second-choice students, they did not gain an appreciable competitive advantage by going elsewhere. Indeed, there is no significant difference in how first and second-choice black students are distributed across the six tiers ( $\left.\mathrm{p} X^{2}=.845\right)$, suggesting that when students opted for a second-choice school they did not, on the one hand, sacrifice much in the way of school prestige or, on the other hand, gain much in the way of a less competitive environment. ${ }^{73}$ Their better performance relative to other students on their first bar attempt is, if it is anything more than a random fluctuation, probably a result of the fact that they are on average stronger students.

In short, Sander's analysis of his second-choice sample does not and cannot do what he wants it to do. It cannot avoid selection bias and it does not provide a rigorous test of his hypothesis because, totally apart from other problems, it is based on assumptions that in many cases are likely to be mistaken. Ayres and Brooks also cannot surmount the problem of selection bias, but given their conclusions, selection bias is not as serious a problem. ${ }^{74}$ Also as Ayres and Brooks report, and as we see from Sander's Table 3 (p.1975), the effects Sander finds are far stronger for first-time bar pass rates than for eventual bar pass rates. ${ }^{75}$ This difference is hard to justify theoretically, suggesting the possibility that Sander's analysis is capitalizing on random error. This is especially likely because, as we pointed out, Sander could have claimed a triumph for his theory had either the relationship to first time bar pass rates or the relationship to eventual pass rates proved significant. This means that the probabilities that the relationships he identifies arose by chance may be taken to be approximately double what he reports, indicating that all but one of the differences he finds may not be statistically significant.

\footnotetext{
${ }^{73}$ It is, in theory, possible that the first-choice schools of the second-choice students were distributed differently than the first-choice schools of all other students, and they in fact did go to much less competitive schools than they would have otherwise attended, but there is no particular reason to think so. It is also true that there are selectivity differences among schools within tiers, but we don't think these would be great in most cases, and they certainly are not great in the small sample of elite law schools which second-choice students are proportionately more likely to attend than first-choice students, though the difference is not significant.

${ }^{74}$ Ayres and Brooks' findings are not threatened by selection bias in the same way that Sander's findings are, for if selection bias affects the Ayres' and Brooks' analysis, there is even more reason to believe that students going to their second-choice schools do no better than students attending their first-choice institutions. But if selection bias affects Sander's results, even if the analyses were otherwise persuasive, the possibility that selection bias explains the better performance of the second-choice sample still exists.

${ }^{75}$ Ayres and Brooks' second-choice analysis, though superior to Sander's analysis on several dimensions, also cannot accomplish its goal of eliminating selection bias. The reason is the same as it was with Sander's analysis; going to a second-choice school is not a random event, but may be possible precisely because a student is stronger on unmeasured variables than those who have had no choice or who, if they had a choice, were not tempted by a better financial package at their second-choice institution. One way in which Ayres' and Brooks' analysis is superior to Sander's is that they compare their second-choice sample students only first-choice students admitted to more than one school. Thus all students in Ayres and Brooks sample were strong enough candidates to be admitted to more than one school. Sander's control group is all other students, many of whom may have been able to secure admission to only one school.
} 
Sander claims his findings regarding second-choice students' rates of graduation and first-time bar passage are "stunning," but they are not nearly so stunning or informative as he would have us believe. Unlike Ayres and Brooks, who compare black students who had more than one law school choice and opted for their second-choice with blacks who had only more than one choice and opted for their first-choice, Sander compares second-choice black law students with all other black law students. We believe Ayres and Brooks have identified a more adequate control group because their firstchoice students, unlike Sander's students, were good enough to get accepted by more than one school and had a choice to make. In addition, Sander does not control for Tier. This may introduce a slight bias because $24 \%$ of first-choice black students are in Tier 5 and 6 law schools, which have particularly low first time bar passage rates, compared to only $21.8 \%$ of second-choice students. For this reason alone, one would expect Sander's first-choice students to fare more poorly on the bar. The second-choice sample also has proportionately less representation at prestige schools than Sander's first-choice sample and proportionately more students at second tier public law schools. Controlling for index scores, black students at prestige schools do worse than expected on the bar relative to students in other tiers and students at $2^{\text {nd }}$ tier public law schools do better than expected. So while the distributions of first- and second-choice students across all law school tiers are not significantly different, if we classify the tiers by whether students tend to do better or worse than expected on the bar given their credentials, we find that the second-choice students are more likely to be in schools that have disproportionately high bar pass rates given credentials and relatively unlikely to be in schools that have unexpectedly low pass rates. This is in addition to the advantage they enjoy over first-tier students on index credentials. ${ }^{76}$

There are still other problems with Sander's second-choice analysis. He is admirably honest in admitting that "the difference in graduation rates between the black second-choice students and the rest of the black students turns on the outcomes of a dozen of the 171 black second-choice students."77 This admission, without saying so, comes close to conceding that his analysis does not make a case against affirmative action. He is saying that if 12 students were not in the second-choice sample, a comparison of the 159 second-choice students remaining with all other black students would show no significant differences in graduation rates. So if there are students who

\footnotetext{
${ }^{76}$ Before leaving this set of criticisms, we should note that the fact that second-choice black students have somewhat higher index scores than other blacks is consistent with our suggestion that some black students are wooed to second-choice schools by financial aid, and that these students are on average more capable than other students, not just on index variables but on other unmeasured variables that predict success. Sander's Table 3, which is adjusted for index score differences, is subject to the same criticism as his Table 2. In addition, it is unclear exactly how Sander produced these corrected results. A comparison of Tables 2 and 3 suggests that it is not just the two black groups whose scores were adjusted for these comparisons but the white group as well since their percentages also change. If this is the case the adjustments for blacks will be dominated by white values. This is problematic, especially since many whites have index scores that far exceed those of almost all blacks. To construct an adjusted pass rate based on the assumption that black and white index scores cover the same range when we have almost no information on how blacks perform is questionable and likely to be misleading. But maybe we do not understand how Sander proceeded because the text indicates that only the black group's scores were adjusted and although he has a footnote (p.1975 n.27) that indicates his procedures, he says so little that we do not know what he did.

${ }^{77}$ Sander, A Reply to Critics, supra note 3, at pp.1976-77.
} 
benefit from being mismatched, it is only a small proportion, about $8 \%$, of those students who, if Sander's assumptions are correct, move from a school where they are mismatched to a school where the mismatch disappears or is lower. But as we have already argued, Sander's assumptions are unlikely to be correct. The figure of 12 is consistent with our speculation that a number of the students who reject a first-choice law school are lured by financial aid offered them because they are especially good bets to graduate and pass the bar, based both on their index scores and on unobserved variables.

Sander raises further pertinent questions about his own analysis:

\begin{abstract}
Are these results too good to be explained by the mismatch theory? After all, the black secondchoice students are still significantly mismatched with their peers. Even though the second-choice students only appear to close about one-third of the academic index gap between blacks and other students in the same tier of schools, and even though their median grades raise them from around the tenth percentile to only around the twentieth percentile in their law school classes, we see the black second-choice students close at least half of the performance gap between blacks and whites. The explanation, I believe, lies in the curvilinear relationship I described in Part II.B, supra. Small improvements in class standing, when occurring near the bottom of the class, have disproportionately large effects upon outcomes. (pp. 1977-78)
\end{abstract}

In this paragraph Sander presents information that further undercuts his claims and reaches additional conclusions that do not follow from his data. First, the selection bias which almost certainly infects Sander's second-choice sample means that if secondchoice students went to their first-choice schools, they could be expected to rank higher in their classes than those students who do go there, so the comparison with the median rank of all other students is not apt. We in fact have no idea what the average difference in median rank between Sander's second-choice black students and all other black students would be if the second-choice students had gone to their first-choice schools. ${ }^{78}$

Moreover, Sander's claim that raising the median score of blacks from what he says is around the $10^{\text {th }}$ percentile to around the $20^{\text {th }}$ percentile matters considerably because of the curvilinear relationship of class rank and first-time bar passage rates ignores the tier dependence which is found in his Table 1. For example, the class rank a student would have to achieve to have at last an $80 \%$ chance of passing the bar on her first try is above the $10^{\text {th }}$ percentile for students graduating from Tier 1 institutions, above the $20^{\text {th }}$ percentile for students graduating from Tier 2 and 3 law schools, above the $25^{\text {th }}$ percentile for Tier 4 graduates, above the $40^{\text {th }}$ percentile for Tier 5 graduates and above the $75^{\text {th }}$ percentile for Tier 6 graduates. So the student at the median of a Tier 1 school who goes to a Tier 2 or 3 school and performs at the median for second-choice students, would be more or less treading water with respect to passing the bar on her first try, but she would be giving up the prestige advantages that go with graduating from a top tier

\footnotetext{
${ }^{78}$ We know from Table 5.4 in Systemic Analysis that among black students graduating law school 39.5\% of them were at or above the $20^{\text {th }}$ percentile in their classes. If Sander's "around $20 \%$ " is a few percentage points below that figure rather than a few percentage points above it, the difference in the median rank of second-choice black graduates and all other black graduates may not be that great, perhaps 5 percentage points or less. If just first-year grades are considered, the proportions of blacks at or above the $20^{\text {th }}$ percentile are $28.6 \%, 33.1 \%, 31.1 \%, 34.8 \%$, 35.8\% and 73.9\% for Tiers 1 through 6, respectively. (All figures are slightly higher than they would be if Sander's second-choice students were not part of the black samples.).
} 
law school. At a Tier 4 school she would give up substantially more in the way of prestige and have to have grades above the median for all second-choice students to have the same expectation of passing the bar her first time through.

The most important point to note about Sander's argument in the preceding paragraph is that coupled with his earlier arguments based on Tables 5.2, he is, without acknowledging it explicitly, weakening substantially his claims for the devastating effects of mismatch and his case for abandoning affirmative action. Sander argues that without affirmative action black students would perform as well (Systemic Analysis) or almost as well (A Reply to Critics) as white students in the same school. Thus, unless he now repudiates his identical performance argument, he is with his data telling us that students in the black "second-choice" sample benefited considerably -- even hugely -- from affirmative action because they still had a median class ranking almost 30 percentage points below where Sander assumes they would be in a world without affirmative action. $^{79}$

The second-choice students' self-selection downward appears from Sander's analyses to close only about one-quarter of the performance gap that Sander attributes to mismatches, but among law school graduates, it eliminates about two-thirds of the difference in first-time black and white bar pass rates, and a little less than half the difference in eventual bar pass rates. It also appears to reduce by about two-fifths the difference between the likelihood that black and white students who enter law school will graduate and become lawyers. For reasons we have already indicated, we don't put much stock in Sander's analyses here, but he and people who are predisposed to believe him do. They should be aware that if one accepts his analyses, Sander has shown that a relatively small diminution in the degree of mismatch will yield substantial improvements in black student success. A reduction this small means that most schools would still be giving blacks a substantial boost with respect to their index credentials in the law school admissions process. His argument would become an argument for tweaking admissions processes rather than for abandoning or even substantially downscaling affirmative action. But given the weaknesses we have seen in his analysis, we do not think even a recommendation for tweaking has been empirically justified.

\section{B. Arguments on the Effects of Ending Affirmative Action}

\section{The Post-Affirmative Action Credential Gap is Sizeable (pp. 1998-2001) \\ (i) Data from the University of California After Proposition 209}

\section{Chambers et al. argue that even in a race-blind regime, there would still be a large black-white} credentials gap in individual law schools and that, consequently, the mismatch problem (if it

\footnotetext{
${ }^{79}$ Sander might argue that if getting a smaller boost from affirmative action benefited blacks considerably, then eliminating all the benefit of affirmative action would help blacks even more. The conclusion would not follow logically from the premise, even if Sander had been able to show blacks benefited from attending less selective schools, which, as we have seen, he has not shown. Nor does Sander present any evidence suggesting that blacks in his second-choice sample performed better if they benefited less from affirmative action.
} 
exists) would still be significant. As evidence, they point out that law schools covered by bans on racial preferences in the late 1990s-e.g., Boalt Hall, UCLA, and the University of Texascontinued to show significant black-white disparities in entering credentials in the years after the bans went into effect. But this is a misleading analogy, for several reasons. The national law schools affected by California's Proposition 209 and Hopwood v. Texas faced a uniquely difficult problem: they were enjoined from using racial preferences, but their direct competitors were not. Thus, underrepresented minority applicants accepted through a completely race-blind method at any of these schools would probably also be accepted by race-conscious Harvard, Yale, and Stanford. As a result, all three schools took extraordinary steps to maintain racial diversity. UCLA, for example, implemented the aggressive socioeconomic diversity program I have written about elsewhere. Such efforts sought to admit some of the students who would have been admitted under the old race-conscious policies, thus necessarily perpetuating a significant credentials gap (p.1999).

Sander's observation about Proposition 209 and Hopwood is partly correct, but upon closer inspection, his arguments does more to support our claims about the credential gap than to call them into question. In a thoughtful 1997 article analyzing admissions at UCLA, Sander wrote that Proposition 209 posed three obstacles for UCLA attributable to the fact that its competitor law schools were able to practice affirmative action: 1) it caused black applications to drop 28\%; 2) students admitted to UCLA "will almost certainly receive simultaneous offers from more prestigious schools that are taking race into account... [and] most minority admittees to a race-blind, score-dependent school are going to accept more prestigious offers elsewhere"; and 3) "prospective minority enrollees are likely to take into account the racial environment they are entering" and "the likelihood that one will be among a very few blacks or Latinos will make other admissions offers more attractive." 80

For the reasons mentioned in our critique of Systemic Analysis (pp.1862-67) we believe that Sander's observations in 1997 are more perceptive with respect to affirmative action bans than his recent comments in A Reply to Critics. For example, we believe that Sander's first and third observations in his 1997 article are accurate, have implications for a national end to affirmative action, and tend to cast doubt on Sander's optimistic projections about the impact of ending affirmative action (Table 8.2). ${ }^{81}$ More to the point, note that Sander's second observation in 1997 pertains to yield problems at UCLA and Boalt (i.e., losing admitted black students to elite schools engaging in affirmative action), just as his reference in A Reply to Critics -- to underrepresented minorities who would likely be admitted at Harvard, Yale, and Stanford -- also refers to a yield problem among admitted students at Boalt and UCLA. ${ }^{82}$ However, since the data we presented on the UC law schools in 1997-99 was for admittees rather than enrolled students (p.1876), Sander's reference to applicants lost to other schools is irrelevant.

\footnotetext{
${ }^{80}$ Richard H. Sander, Experimenting with Class-Based Affirmative Action, 47 J. LEGAL EDUC. 472, 492 (1997).

${ }^{81}$ See id. at 493-94 ("If the enrollment figures [post-affirmative action] of a group fall below a certain threshold (as is likely with blacks), and members of that group have other attractive options, one should expect enrollments to fall to zero or very close to zero.”).

${ }^{82}$ Id. at 492. See also id. at 493 n.42 ("Boalt Hall's experience in 1997 illustrates this point. Amid considerable publicity about the likely drop in minority enrollments, none of Boalt's 15 black admittees enrolled.”).
} 
There are other problems with Sander's criticism of our discussion of the credential gap and admission data. In addition to providing data from three University of California law schools (Berkeley, UCLA, and Davis), ${ }^{83}$ we also cited actual data from UC medical schools, undergraduate data from UC Berkeley and UT-Austin, and BPS data. Sander does not comment on these other data sources, and perhaps more importantly, he offers no response to our review of the expert opinion from a range of disciplines (Bowen and Bok, the Thernstroms, Fischer et al., Dickens and Kane, Liu, and Steele, several of whom empirically modeled admission scenarios) which strongly suggests that even without affirmative action the credential gap remains substantial, not just real (see pp. 1874-77). The combination of real data and scholarly consensus suggests that Sander can only be right if nearly everyone else is wrong; he does not provide enough detail to meet his strong burden in proving that he is in fact right.

Sander's claim that the credential gap we reported was due to the UC law schools taking "extraordinary steps" in the years immediately after Proposition 209 is also overreaching; such measures, while certainly commendable, were short of extraordinary. ${ }^{84}$ Keep in mind that in 1997-99 at Boalt, UCLA and Davis, African Americans were $2.6 \%$ of admittees and $2.2 \%$ of first-year enrollments, a precipitous drop from $8.1 \%$ of admittees and enrollments in 1994-96, ${ }^{85}$ and the post-209 figures at UC were within the same range as Lempert, Chambers, and Adams' estimate of the proportion of students at Michigan over a 27 year period who might have been black had Michigan admitted its students without affirmative action. ${ }^{86}$ They are similarly

\footnotetext{
${ }^{83}$ Sander incorrectly states that we analyzed admissions at the University of Texas Law School when in fact we did not (for lack of data).

${ }^{84}$ UCLA's class-based affirmative action program was path-breaking in some ways, such as the depth of applicant background information it attempted to collect and systematize, but did little to alter the number of African American students admitted. Sander has previously characterized UCLA's program as "designed to be academically neutral" (i.e., it kept the mean index score of the class the same as prior years). Id. at 498, 486. UCLA set the minimum eligibility threshold for socioeconomic consideration at 625 (on Sander's 0-1000 scale), where in the past it had admitted some African Americans with index scores of 550 or below. Id. at 495, 497. Finally, Sander said this in 1997: "If thoughtful people continue to experiment with class-based preferences and share what they learn, UCLA's first walk down this path will be seen as tentative baby steps indeed." Richard H. Sander, Comment in Reply, 47 J. LEgAL EdUC. 512, 513 (1997).

Changes at Boalt Hall included giving academic index scores "substantial weight" instead of "greatest weight," reporting LSAT scores in bands as LSAC had begun doing (i.e., a 160 reported as 157163), ending the practice of adjusting UGPAs by rank of the student's undergraduate institution (a practice that had penalized graduates of California State Universities and historically black colleges), sending a larger share of files to the admission committee, and a variety of energetic recruitment efforts by law students, admission staff and prominent alumni. See e.g., ANDREA GuERRERO, SilenCE AT BoAlt Hall: The Dismantling of AfFirmative Action (2002); Herma Hill Kay, The Challenge to Diversity in Legal Education, 34 InDianA L. REV. 55, 64-65, $73-78$ (2000). The admissions changes at UC Davis mirrored those at Boalt. Kay, id. at 78.

${ }^{85}$ Univ. of California Office of the President, UC Law School Enrollments (2003), available at http://www.ucop.edu/acadadv/datamgmt/lawmed/ (194 of 7,761 admission offers and 51 of 2,269 enrollments in 1997-99). At least 3 of the black enrollees in 1997 were admitted in 1996, when affirmative action was practiced, and then deferred enrollment.

${ }^{86}$ Richard O. Lempert et al., Response: Answers to Methodological Queries, 25 LAW \& SoC. INQUIRY 585, 594-95 (2000).
} 
consistent with Sander's estimates that about one to two percent of elite school classes today would be black if affirmative action were eliminated nationwide. ${ }^{87}$

Moreover, we limited our focus to the 1997-99 admission cycles at UC law and medical schools, in order to show that even in a "hard case" from the real world, the credential gap among admitted students was nonetheless substantial. We limited ourselves to 1997-99 in light of the claims made by Sander that UCLA and Boalt were skirting Proposition 209 in the years thereafter. ${ }^{88}$ In summary, we believe that our data from California and Texas -- prior to the years that more expansive race-neutral measures were adopted -- establish that the credential gap is substantial even when taking a rather conservative approach, more so in light of our review of expert opinion. ${ }^{89}$

\section{Why 2004 Admissions Data is Preferable to Sander's 2001 Data (pp. 2002-03)}

I have not had the leisure to check their calculations, but let us suppose for the sake of argument that their Table 1 is accurate. If we look over the past ten admissions cycles (1995 to 2004), we see that the 2001 estimates Wightman and I used are at the median for that period, and about

\footnotetext{
${ }^{87}$ Sander, Systemic Analysis, supra note 2, at 483.

${ }^{88}$ Richard Sander, Colleges Will Just Disguise Racial Quotas, L.A. TimEs, June 30, 2003, at B11; Daniel Golden, Case Study: Schools Find Ways to Achieve Diversity Without Key Tool, WaLl ST. J. June 20, 2003 at A1 (quoting Sander's criticism of the Critical Race Studies prong of UCLA Law School's admission policy). For similar reasons, we provided data on the initial post-affirmative action freshmen classes at UC Berkeley with athletes removed (before the UC Regents adopted the Four Percent Plan and a holistic admissions approach called "comprehensive review"), and focused on the 1997 freshmen class at UTAustin (admitted before the Texas Ten Percent Plan took effect) (see p. 1876 notes 77-78).

${ }^{89}$ Sander also attempts to support his claim through an admissions simulation. He does not post enough information about his data and methods to allow us to replicate his effort or fully evaluate it. Sander first posted his simulation results on the web in January 2005, and then cited this simulation in print in A Reply to Critics to refute our claims. Yet, despite his reliance on this data in the pages of the Stanford Law Review and despite our repeated requests for his data and methodology, Sander will not share his data or calculations until he publishes them in a subsequent academic article on affirmative action.

However, what he does reveal suggests the simulation is seriously flawed for it assumes that index scores explain $80 \%$ to $90 \%$ of the variance in law school admissions decisions (even before applying Sander's grade adjustment method) when we know from Wightman's examination of real law school data for the 2001 admissions cycle that the proportion of variance that index scores explain was $69 \%$ for whites and $62 \%$ for Asian Americans, and that the corresponding figures in the 1991 BPS cohort were $61 \%$ and 44\%, respectively. Linda F. Wightman, The Consequences of Race-Blindness: Revisiting Prediction Models with Current Law School Data, 53 J. LegAL Educ. 229, 2336 tbl.2 (2003). Wightman had individual applicant's exact LSAT scores and UGPAs, which contradicts Sander's assertion in Systemic Analysis (pp. 406-07) that if he had such information rather than index scores reported in bands, he would show that the variance in admission decisions explained by index scores is above $90 \%$. See also Ian Ayres \& Sydney Foster, Don't Tell, Don't Ask: Narrow Tailoring After Grutter and Gratz, Yale Law School John M. Olin Center Working Paper No. 287, at 39-40 (Sept. 2005), available at http://lsr.nellco.org/yale/lepp/papers/287/ (analyzing the same University of Michigan Law School admissions data that Sander analyzed and finding that $49-50 \%$ of the variance in Michigan Law School's admission decisions can be explained by race, GPA, LSAT scores, residency, and year). Ayres and Foster's findings contrast with Sander's, claim in Systemic Analysis (p. 406), that 88\% of admissions outcomes can be correctly predicted for the Law School in 1999 on the basis of academic factors and race). In light of the above data, assuming that about $65 \%$ or less of the variance in admission decisions would be explained by index scores post-affirmative action is therefore more realistic than Sander's assumption of 80-90\%.
} 
three percentage points below the average. It is fair for Chambers et al. to point out that the numbers bounce around from year to year, but why is it reasonable to claim that we should use the highest figure of the past decade? (p. 2002).

Sander claimed in Systemic Analysis that if affirmative action ended when he wrote (Fall 2004), only 14\% fewer African American law school applicants would be admitted (and enroll) at ABA law schools. ${ }^{90}$ Our Table 1 (p.1861) includes annual data from 1991 to 2004 and indicates that in each of the past five admission cycles (20002004) the percentage of African American admittees who would be excluded under the grid model was worse than the prior year. Not only does Sander mislead when he refers to 2001 estimates "that Wightman and I used", since the reader might think their methods and results were similar, ${ }^{91}$ but he fails to explain how using 2001 data to estimate the situation in 2004 is superior to using 2004 data. It is not. Sander's intended claim that 2001 data is better than 2004 data for estimating the effects of affirmative action in some arbitrary future year is, however, reasonable - if it is accurate. We have good reason to believe that in the foreseeable future, it is not accurate just as it was not accurate when he wrote. In each year since 2001 the proportion of admitted African Americans who would have been excluded from all law schools under the grid model has increased: up to a 19.1\% decline in 2002, a 24.1\% decline in 2003, and a 32.5\% decline in 2004 (pp.1861$62)$.

In fact, data from the 2005 admissions cycle just became available. Even though total applicant volume dipped a bit from 100,000 in 2004 to 95,000, the 2005 data indicate that admission offers to African Americans would decline by $29.4 \%$ under the race-blind model endorsed by Sander. This is just over double Sander's estimate of a 14.1\% decline using 2001 data.

Table 1 in our Stanford Law Review essay indicates that in the years when total applicant volume was roughly 85,000+ (1991-1995 and 2002-2004), the grid model results were much worse for African Americans (declines of 19\% to 53\%), compared with the years when total applicant volume was under 80,000 (9\%-14\% declines in 19962001), and the same is true of 2005. One question is whether the current admission environment should be characterized as a relatively high application period or whether it is normal or even low. Certainly the picture presented by the data from the late 1980s on suggests that the trough in the latter half of the 1990s was an aberration, most likely associated with elevated student interest in the then booming non-legal sectors of the economy, and that what we have been seeing since 2002 is a return to normalcy. It is also plausible to suppose that as the United States population continues to grow and college attendance increases, fueled in part by the educational aspirations of immigrants

\footnotetext{
${ }^{90}$ Sander, Systemic Analysis, supra note 2, at 475-78; see also Richard H. Sander, House of Cards for Black Law Students, L.A. TimEs, Dec. 20, 2004, at B11.

${ }^{91}$ This choice of words overlooks the facts that (1) Wightman explicitly notes that the grid model estimates are too conservative because of the assumptions it makes about where minority students would apply; (2) Sander, unlike Wightman, extends the grid model beyond admission offers to enrollments; and (3) Sander's "cut out the bottom" method is not faithful to Wightman's grid model methodology (see pp. 1862-63, 1889-90).
} 
and their children, applications to U.S. law schools will further increase ${ }^{92}$ with a possible diminution in the proportion of the applicant pool who are black (especially among those who are competitive at highly selective law schools).

But suppose we are unwilling to extrapolate from recent trends and take the data at face value; namely, as an indication that substantial fluctuations in applicant pool size, and in the proportion of blacks in the applicant pool, are likely to occur. This raises a second question: are the resulting fluctuations in black law school attendance desirable? Do we want, as a matter of public policy, substantial periods when there are very few black students in law schools, especially in the most selective law schools, even if those periods are followed by other periods in which the number of black students admitted is considerably higher? During the low years, the few black students will feel isolated and conspicuous. Moreover, the black students excluded in the low years will be not differ substantially in ability compared with the black students admitted in the high years, and by Sander's own analysis most of the black students excluded in high white application years would, had they enrolled, been able to graduate and pass the bar.

Sander appears strongly predisposed to sticking with 2001 data even while acknowledging that our criticism of his estimates of the effects of eliminating affirmative action on black bar passage is our strongest point. We shared our 2002-2004 data with Sander several months before A Reply to Critics was published, and we are certainly willing to share 2005 data with him. Sander is now completing research for a book on affirmative action. We trust that he will make use of data from 2005 or at least a more recent year than 2001 in the finished product. If he persists in relying on 2001 data, that choice will be revealing.

\title{
3. The Decline in Enrollments at Elite Schools (p. 2003)
}

\begin{abstract}
[T]hey [Chambers et al.] slip into the apocalyptic school in other respects. They simulate (in their Table 7) their projected distribution of black students across law school tiers. But their total (1295 students) is more than 600 students shy of the total number of blacks they project would start law school in a race-blind regime. This apparent error obviously understates the actual representation of blacks in the various law school tiers. Second, their projected 45\% drop in firstyear black enrollment assumes that substantial numbers of blacks will stay away from law school in a race-blind regime. But the best research on the effects of race-blind admissions on black applicant behavior finds no net change at all, at least for highly qualified applicants. (p.2003)
\end{abstract}

In Systemic Analysis, Sander conceded that, if affirmative action were ended, African American enrollments at the fourteen highly elite schools in Wightman's Tier 1 would probably decline from their current level of around $8 \%$ down to around $1-2 \% .{ }^{93}$ And while the overall black graduation rate in the BPS was $80.7 \%$, at the elite Tier 1

\footnotetext{
${ }^{92}$ See Michael A. Olivas, Law School Admissions After Grutter: Student Bodies, Pipeline Theory, and the River, 55 J. LEGAL EDUC. 16, 21 (2005) ("[T]he most important law school enrollment indicators are all robust. The applicants in 2003-04 totaled 96,400, generating 147,600 LSATs. All of these indicators are historic highs. To be sure, as Figure 2 shows, there is a cycle here, with ebbs and flows, but the outlook for legal education is strong and likely to get stronger with the continued growth in its rootstock-the rising number of 22-year olds.”).

${ }^{93}$ Sander, Systemic Analysis, supra note 2, at 483.
} 
schools (where a majority of African American students now enrolled would be excluded without affirmative action), the black graduation rate was an impressive $95.3 \% .^{94}$ Indeed, in what some might consider a bit of a bombshell, Sander's 2001 admission simulation posted on his website in conjunction with A Reply to Critics suggest that without affirmative action, he projects there would be zero ${ }^{95}$ (or nearly zero ${ }^{96}$ ) African Americans law students at Harvard and Yale. In fact, there have been about 208 African Americans in the student body at Harvard Law School and Yale Law School in each of the past few years. ${ }^{97}$ The impact of ending affirmative action at the most elite schools should concern not just policymakers but anyone who values racial equality and the contributions of African American leaders in the legal profession and African American intellectuals. $^{98}$ As we noted in our essay, of the 604 current African American law professors at ABA law schools, 48\% graduated from the U.S. News top ten ranked law schools (p. 1896 n.145), and in his review of Sander's article, Professor David Wilkins reports similar findings among partners and associates at top law firms (pp. 1933-37). In fact, $25 \%$ of current black law professors in the U.S. graduated from Harvard or Yale.

In his article, Sander made no tier-specific attempt to compute the probable decline in black enrollment at schools other than the first tier, but he implied that the drop at other schools would be modest or nonexistent. In his Reply, Sander addresses our claim that substantial enrollments declines would occur not just at the most elite 14 schools, but probably at the most selective fifty or even eighty. However, he presents no competitive forecast of effects at this level. Two-thirds of his attack on our analysis consists of citing an irrelevant study of undergraduate application behavior and shouting "apocalyptic."

Only two points of Sander's criticism merit reply. He says there is an obvious error in our Table 5 (p.1894), in that it projects a total of only 1295 black students in American law schools, a figure that is about 600 students less than an estimate we give elsewhere. However, there is no error in our calculations, which assume that law school admission is entirely a function of LSAT score and UGPA. The resulting figures that support Table 5 are based on different assumptions and methods of calculation than those that produced the estimates in Table 4, as explained at page 1894.

Our estimate of 1295 African American law students is in some ways "purer" than the higher estimate in Table 4 because it assumes that only LSATs and UGPAs are taken into account in admissions, and these are known hard numbers. However, we feel

\footnotetext{
94 Sander, Systemic Analysis, supra note 2, at 437 tbl.5.5.

95 Sander, Estimating the Distribution Gap, supra note

96 Based upon conversations with Sander about his admission model, we understand that the at the law schools where he did not post a black index score average on his website (e.g., Yale, Harvard, Cornell), the number of blacks admitted was so small that he could not reliably estimate an index score.

${ }^{97}$ Progress of Black Student Enrollments at the Nation's Highest-Ranked Law Schools, 1999-2004, 46 J. BLACKS IN HigheR EDUC. 34 (Winter 2004-2005). This figure is for total J.D. students, not first-year students.

${ }^{98}$ Likewise, Wilkins and Gulati found that $47 \%$ of African American partners at major corporate law firms went to Harvard and Yale. David B. Wilkins \& G. Mitu Gulati, Why Are There So Few Black Lawyers in Corporate Law Firms?, 84 CAL. L. REV. 493, 563-64 (1996).
} 
the Table 4 numbers are superior because law schools do not admit only on the index credentials, and in our Table 4 estimates we tried to allow for that reality. We agree with Sander that the estimated enrollments produced by a pure index score model are too low. To compensate, when we produced Table 5, we added a row that doubled the number of students predicted to be admitted in each law school tier, which produced a number considerably higher than our Table 4 estimate and ensured that any errors would be on the conservative side. We based our claims on that doubled figure. What we see is that even with doubling the number of probable black students, there would be a huge decline over the current numbers of black students not just at a handful of elite law schools, but much further down the ranks. Sander knew this because we say it clearly and one cannot miss a row in our table. Yet in A Reply to Critics he never mentions our adjusted model and what it shows.

Sander also rejects our forecast of a major decline in African American enrollment at 50 or more schools because he claims that it rests on our earlier prediction of a substantial decline in black law school applications if affirmative action is abolished. to law school (p. 2003). For reasons stated in an early section of our article, we believe that without affirmative action black law school applications would decline, ${ }^{99}$ but we did not assume such a decline in making our estimates in Table 5. Those estimates assume that the number of black applications are unchanged and that all admitted black students matriculate. If the number of especially able black applicants fell with the end of affirmative action, the decline of black students at the elite and other high ranking schools would be even more drastic than our table projects.

\title{
4. The Worsening Mismatch Effect? (p. 2004)
}

\begin{abstract}
Chambers et al. claim that, in estimating the enrollment of black law students and the production of black lawyers in a race-neutral world, I consistently err on the side of optimism. I strongly disagree. My assumption about the proportion of blacks who would be admitted in a race-blind regime is much closer to historical norms than Chambers et al.'s assumption. My assumptions about black applicant behavior in a race-neutral regime are supported by research; Chambers et al. 's are not. In one very important respect, Table 8.2 in Systemic Analysis probably understates the current mismatch problem, and the positive effects on blacks of moving to a race-neutral system. This is in my reliance on bar passage data from 1994. Because 1994 is the year when students in the LSAC-BPS generally graduated and took the bar, it is the only year for which we have a good national measure of the relative bar passage rates of whites and blacks. All of the findings about bar exam results in Systemic Analysis, and in much of the ensuing debate, are based on the 1994 numbers.

The current situation is much more severe. As Chambers et al. well know, 1994 was the historical high-water mark of national bar passage rates [citing Kidder 2004]. The first-time bar passage rate measured by the LSAC-BPS was about 88\%; the total national rate in 1994-1995 was somewhat lower-82.3\%-for a variety of reasons; the rate has steadily fallen since then, to 74.7\% in 2002-2003. If a sample in which the first-time bar passage rate is $88 \%$ produces a black first time bar passage rate of about $61 \%$, what is the passage rate going to be when the
\end{abstract}

\footnotetext{
99 Sander says that "the best research on the effects of race-blind admissions on black application behavior finds no net change at all, at least for highly qualified applicants.” The research on which Sander relies solely relates to undergraduate admissions, where many factors are different. Even so, we presented evidence that the effect of ending affirmative action on undergraduate application (and yield) rates was more ambiguous than Sander acknowledges (pp. 1864-65 n.32).
} 
national rate is under 75\%? My own guess is that only a third of black law students are now graduating and passing the bar on their first attempt, and significantly less than half of entering black law students now become lawyers. (p. 2004)

Sander is correct that Kidder's Law \& Social Inquiry article indicates that 1994 (the entering class of 1991) was the year with the highest national bar pass rates in the U.S. in the last couple decades. ${ }^{100}$ But Sander does not claim an effect of mismatch on eventual bar passage because his empirical analysis finds no significant differences between his first and second-choice samples when eventual bar passage is the dependent variable. Thus, even accepting Sander's empirical claims (and we certainly do not), one would not expect changes in the relative difficulty of the bar exam to exacerbate the effects of mismatch on lawyer production because no effects have been shown. Sander does, however, point to a genuine problem even if his prescribed cure would not help. A reduction in bar exam pass rates will hurt the chances of both white and black students to pass the bar. All else being equal, it is likely to hurt proportionately more blacks than whites, though in absolute numbers whites are almost certain to be affected more.

The solution, however, has nothing to do with affirmative action. Rather it involves determining whether the bar exam standards of a decade ago were in fact letting large numbers of incompetent lawyers enter the profession, and, if so, whether raising the bar pass level effectively weeds out most attorneys who should not be practicing. If higher standards weed out many who should not be lawyers while excluding few who should be, then the higher bar pass standards are likely to be, on balance, merited. We know, however, of no good evidence that this improvement in bar standards has happened, nor do we think that strong evidence motivated bar examiners in states that raised their bar pass standards. ${ }^{101}$

What is relevant is the likely accuracy of Sander's completely unsupported speculation (his "own guess") that only a third of entering black law students are passing the bar on their first attempt and fewer than 50\% ever become lawyers. His guess is based on bar pass rates in the 1991 entering cohort and the reasonable assumption that among students who passed the bar black students were likely to have had lower passing scores than white students, just as they had lower law school grade-point averages. If many of these black bar passers were on the cusp of failing, then it seems possible (and in Sander's mind likely) that the raising of bar pass standards over the past decade will have drastically increased the proportion of black law students who do not become lawyers. But Sander ignores crucial data.

First, Sander appears to ignore the fact that a large proportion of the black law students who never pass the bar examination never take a bar examination because they never completed law school. It is possible that greater wealth in the black community,

\footnotetext{
${ }^{100}$ William C. Kidder, The Bar Examination and the Dream Deferred: A Critical Analysis of the MBE, Social Closure, and Racial and Ethnic Stratification, 29 LAW \& SOC. INQUIRY 547, 550 fig.1 (2004).

101 See e.g., Kidder, Bar Examination and the Dream Deferred, supra note _ , at passim; Kristin Booth Glen, When and Where We Enter: Rethinking Admission to the Legal Profession, 102 CoLUM. L. REV. 1696 (2002); Deborah J. Merritt et al., Raising the Bar: A Social Science Critique of Recent Increases to Passing Scores on the Bar Exam, 69 U. CIN. L. REV. 929 (2001).
} 
better financial aid packages and better performance by black law students, because they are as a group more skilled, has reduced black drop out in the recent years. We know, however, of no data that test this proposition. To the extent black drop out rates have fallen, if they have fallen, the increased difficulty of the bar exam will in some measure be offset.

Just as important, Sander is assuming that the ability of black law students both absolutely and relative to whites has remained constant over the past 15 years, an incorrect assumption that his analysis of the 2001 cohort, or a careful reading of our response, should have made clear. We mentioned in a footnote in our article that index scores for new African American law students were by 2004 significantly better than they had been in the 1991 BPS entering cohort. (p.1891 n.122). We shared our 2004 LSAC data with Sander last February, so he could check us if we were wrong. These data show that in the 1991 BPS, 77.7\% of entering African Americans law students had index scores of 500 or higher. ${ }^{102}$ By contrast, in the 2004 entering class, even with affirmative action, 96.4\% of entering African American law students had scores of at least $500 .^{103}$ Similarly, the recently released data on the 2005 admission cycle indicates that $91.7 \%$ of enrolled African Americans had index scores of 500 or above.

This has important implications for expected black bar performance. In the 1991 BPS, only 36\% of African American law students with index scores in the 400s (and 17\% of those in the 300s) graduated and eventually passed a bar exam, compared to an eventual pass rate of $53 \%$ for black law students with index scores in the 500 s. $^{104}$ Among black law students $22.3 \%$ had an index score below 500 in 1991, compared to $3.6 \%$ in 2004 (and 8.3\% in 2005). By contrast, index scores for whites were unchanged in the early 1990s and 2004. ${ }^{105}$ Thus when it comes to the likelihood that a black law school matriculant will graduate and pass the bar, the increased stringency of the bar exam in some states should be offset in some measure, and maybe in some states entirely or more than entirely, by a higher likelihood of remaining in school and better performance on the bar. We can thus expect that in this new bar exam climate the relative

102 In Systemic Analysis Sander attributed nearly one-sixth of the black-white bar passage gap to the admission of black students with index scores below 500, a pattern he blamed on affirmative action. Sander, Systemic Analysis, supra note 2, at 447-48.

${ }^{103}$ In Systemic Analysis, id. at 474 Sander claims that it is black law students with index scores of 480 or below who would “make up the bulk of those excluded under a race-blind system.” This can't be true given how few students in the entering 2004 cohort had scores at this level and how many students are predicted by the grid model to be excluded.

104 Richard Sander, Excel Spreadsheet for Systemic Analysis Table 8.2 (2005), available at http://www1.law.ucla.edu/ sander/Systemic/Supp.htm.

${ }^{105}$ Sander's article only provides the 1000-point index score formula for the 120-180 LSAT scale, not the 10-48 scale LSAT used in the 1991 admission cycle, and the spreadsheets on the 1991 BPS provide more information for blacks than for whites. Thus, we compared 2004 with the 1992 fall entering class instead of 1991. In 1992, 93.9\% of whites had index scores of 600+, compared to 92.7\% in 2004; in both 1992 and 2004 99.6\% of whites had index scores of 500+. Note that other evidence suggests that white index scores for law students were highest in 1991, so using 1992 as a comparison group is being conservative for purposes of our criticism of Sander. See Kidder, Bar Exam and the Dream Deferred, supra note _, at 555 n.16; Sander, Systemic Analysis, supra note 2, at 447 (noting that in the 1991 BPS only 0.2\% of whites had index scores of 500 or below). 
gap between whites and black bar passage rates has decreased, that a number of black students who would have passed the bar in 1994 will not pass it today, that the same is true of white students, and that numerically more white than black students are likely to be hurt by the new standards while proportionately the situation is likely to be reversed. We can also say that had bar pass standards remained as they were in 1994 the gap between black and white bar passage rates would have shrunk even more. What we cannot say is the one thing Sander would have us say: that the likelihood that a black law school student today will graduate and pass the bar is much lower than it was in 1994. We do not know, and much of what we know does not support this expectation.

The UCLA School of Law provides a helpful illustration of how this shift plays out at an individual law school. The admissions policy at UCLA, set by a faculty committee, treats an index score of 600 as "a number that approximates the lowest range of admissions [UCLA has] permitted in recent years ... to be overcome only by strong and specific evidence of intellectual attainment, such as performance in study at the graduate level.”106 The percentage of enrolled African American law students in the U.S. with $600+$ index scores improved from $41.4 \%$ in 1991 to $62.4 \%$ in 2004 and $59.7 \%$ in 2005. Thus, while about two-fifths of the African American law students at ABA schools would have been at least minimally qualified for study at UCLA in 1991, about threefifths would have been minimally qualified in 2004-2005. Numbers like these challenge Sander's gloomy guess that "significantly less than half of entering black law students now become lawyers" notwithstanding the fact that some states have made their bar exams more difficult to pass. African Americans admitted to law school today appear as a group significantly stronger than they did just 15 years ago, even if affirmative action is still an essential tool to ensure they are present in more than token numbers at many law schools.

\section{CONCLUSION}

In this response to Sander's A Reply to Critics we have noted only some of the objections that can be made to the claims he set forth. In particular, we have focused almost all of our attention on his new analyses and replies specifically directed at our critique. But in reviewing his response, we noted many places where he was equally unconvincing in replying to his other critics. Sander acknowledges some mistakes in Systemic Analysis, but then designs new analyses that seemed to be aimed more at reinforcing his conclusion that affirmative action harms black students than at rigorously testing whether this conclusion is true. Thus he focuses his analysis in Reply on first time bar passage rates alone rather than conjunction with analyses of eventual bar passage rates which are less supportive of his conclusion. He also ignores the statistical implications of examining two dependent variables and presenting data only on one. Moreover, many of the criticisms we made of his original analysis and use of statistics, like treating significance levels as if they measured a variable's practical importance, are not addressed because, we think, he had no answers. Some of the issues Sander attempts

106 Carole Goldberg et Al., Report of the UCLA School of LAW Admissions TASK ForCE 8 (Jan. 2001). 
to deal with in his reply, like the issue of selection bias, are difficult issues to get hold of statistically. It is to Sander's credit that he tried, but in doing so he made some questionable choices about how to proceed and in the case of selection bias his methods failed to avoid the problem.

Ultimately we believe that the flaws in Sander's Reply are as serious as those in Systemic Analysis. In neither does he provide convincing evidence for a mismatch effect, for his claim that affirmative action on average hurts black students, or for his prediction that without affirmative action the number of black law students passing the bar each year would not fall by much and might even rise. Yet, Sander state's his conclusions with great confidence. This confidence is unwarranted, and the truth we believe is often the opposite of what Sander posits. On many issues, we are not as confident as Sander seems to be that these data provide answers clear enough to be helpful to today's policy makers. The data and the way it is coded are such that it cannot definitively answer many of the questions we and Sander ask of it, and given that the most recent information is more than a decade old even if it could provide answers for the cohort of students entering law school in 1991 it would be fair to ask if the answers held today. But on one issue we are confident and do benefit from contemporary data. If affirmative action were abolished and race were not given some weight in law school admissions, the number of black students graduating law school and passing the bar would diminish substantially as would the number of black students getting elite legal educations. 